Portland State University

PDXScholar

\title{
Learning work in the ESL classroom : an evaluation of textbooks designed to teach ESL in the workplace
}

Amy Taylor-Henry

Portland State University

Follow this and additional works at: https://pdxscholar.library.pdx.edu/open_access_etds

Part of the Applied Linguistics Commons, English Language and Literature Commons, and the First and Second Language Acquisition Commons

Let us know how access to this document benefits you.

\section{Recommended Citation}

Taylor-Henry, Amy, "Learning work in the ESL classroom : an evaluation of textbooks designed to teach ESL in the workplace" (1995). Dissertations and Theses. Paper 3604.

https://doi.org/10.15760/etd.5488

This Thesis is brought to you for free and open access. It has been accepted for inclusion in Dissertations and Theses by an authorized administrator of PDXScholar. Please contact us if we can make this document more accessible: pdxscholar@pdx.edu. 


\section{THESIS APPROVAL}

The absract and thesis of Amy Taylor-Henry for the Master of Arts in Teaching English to Speakers of Other Languages were presented November 29, 1995, and accepted by the thesis committee and the department.

COMMITTEE APPROVALS:

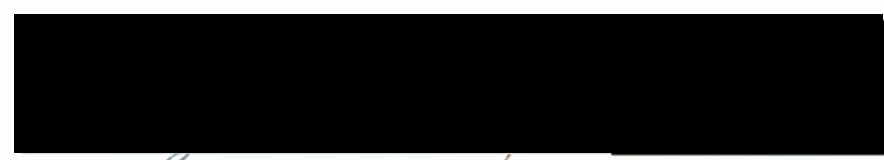

Marjorie Terdal, Chair

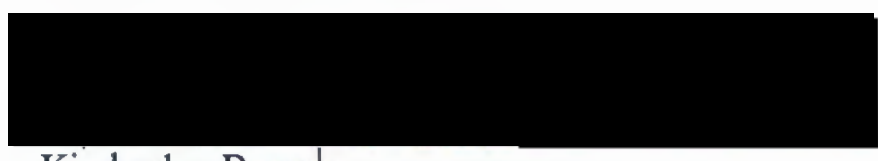

Kimberley Browp

DEPARTMENT APPROVAL:
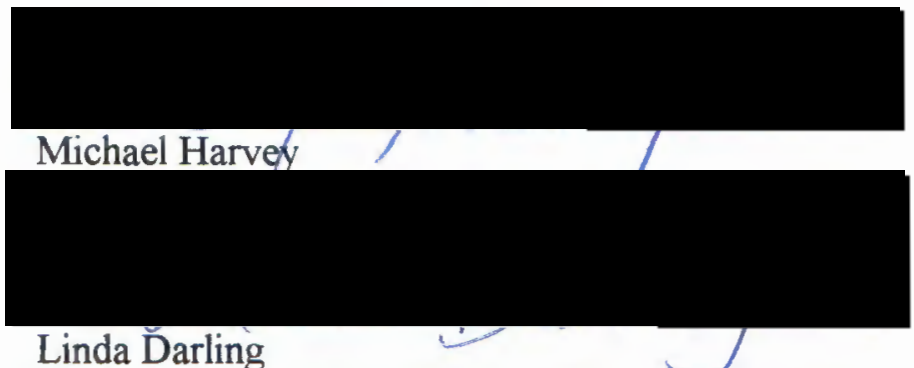

Representative of the Office of Graduate Studies

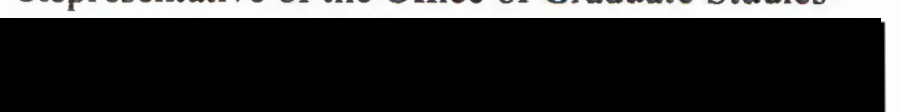

Beatrice T. Oshika, Chair

Department of Applied Linguistics 
An abstract of the thesis of Amy Taylor-Henry for the Master of Arts in Teaching English to Speakers Of Other Languages presented November 29, 1995.

Title: Learning Work in the ESL Classroom: An Evaluation of Textbooks Designed to Teach ESL in the Workplace

A growing number of American businesses are offering ESL courses at the work site; likewise, more and more textbooks designed specifically for teaching ESL in the Workplace (EWP), are being written and published. The need for an evaluation of these new texts with regard to current teaching methodology, the particularities of EWP, and the social implications of EWP is a vital one. A good EWP text, besides serving as a guide and resource for learners, can also facilitate intercultural understanding, increase awareness of workers' rights and unions, and promote participation in training programs for job flexibility and promotion. Most importantly, a good EWP textbook can develop the skills necessary for learners, not simply to fit into the American world of work, but to become active participants in their workplaces.

This study was intended to determine what EWP texts are currently available, and to evaluate them in light of three primary concerns: the social implications of their contents, their portrayal of workplace culture and relationships, and their effectiveness in exploring issues of conflict and unfairness at work 
Twenty textbooks were evaluated in this study. The evaluation process was twofold; first a descriptive evaluation was conducted for all twenty texts. Then, an indepth evaluation was written for ten of the twenty texts. Results of the descriptive evaluation appear as a matrix. The ten in-depth evaluations were written as independent book reviews.

This evaluation concludes that, with only a few exceptions, recent EWP textbooks fail to prepare learners for success and survival in the American workplace. The texts fail to increase worker flexibility by not including literacy skills, job search strategies, or advancement. The texts fail to make learners active participants in their workplaces by not exploring such issues as unions, rights, and intercultural communication. Finally, textbook writers and publishers may be attempting an impossible neutrality by avoiding such topics.

EWP textbooks represent a new genre of ESL materials. This study should not only help EWP teachers select textbooks, but also inform TESOL professionals and publishers of concerns in EWP. 
LEARNING WORK IN THE ESL CLASSROOM:

AN EVALUATION OF TEXTBOOKS DESIGNED TO TEACH

ESL IN THE WORKPLACE

by

AMY TAYLOR-HENRY

A thesis submitted in partial fulfillment of the requirements for the degree of

MASTER OF ARTS

in

TEACHING ENGLISH TO SPEAKERS OF OTHER LANGUAGES

Portland State University

1996 
To my parents, Irene and Romeyn Taylor 


\section{ACKNOWLEDGMENTS}

My greatest thanks and deepest appreciation go to my advisor, Professor Marjorie Terdal, for her unfailing support and assistance. Much of this thesis was written longdistance and I am especially grateful for her patience with and ability to respond so well through the mail. Her encouragement, advice, and kindness were crucial to the completion of this thesis. I also wish to thank Professor Kimberley Brown whose help and encouragement have given me confidence and greatly improved this thesis. Likewise, I would like to thank the other members of my committee, Michael Harvey and Professor Linda Darling for their insights, comments, and advice.

I also thank my parents and family for their constant support and for setting such inspiring examples for me to follow. They have always been great believers in me. Their faith and prodding are very necessary ingredients in my life, and big parts of any accomplishment I manage. Finally, I thank my husband, Mark, for his patient help with the computer, for always encouraging me to reach for more, and for making it all a joy. 


\section{TABLE OF CONTENTS}

CHAPTER

PAGE

ACKNOWLEDGMENTS …...................................................... ii

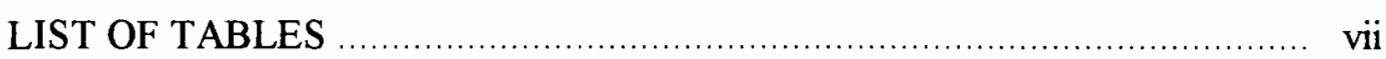

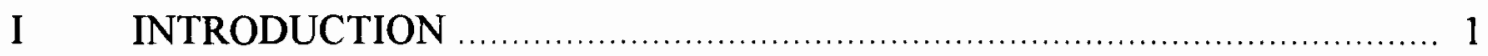

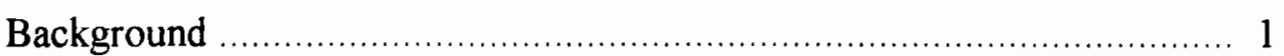

The Research Questions ............................................................ 9

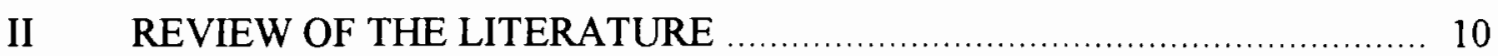

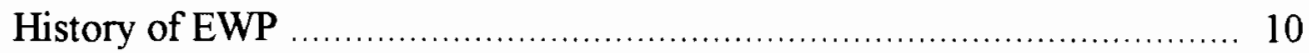

Background to Current EWP Programs ......................................... 14

Workplace Culture ................................................................. 17

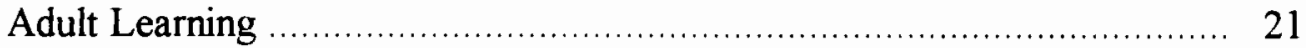

EWP Needs Assessment ............................................................ 27

Textbook Selection and Evaluation ............................................ 29

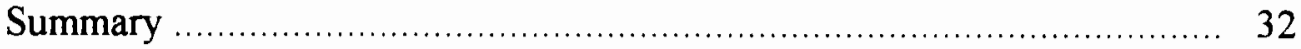

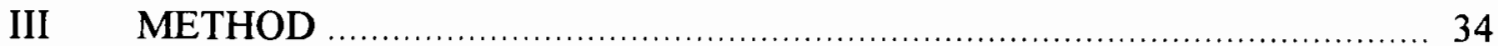

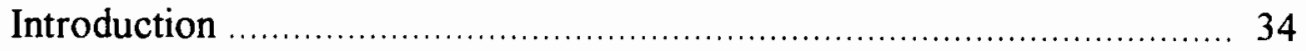

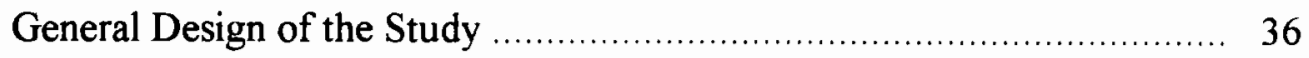

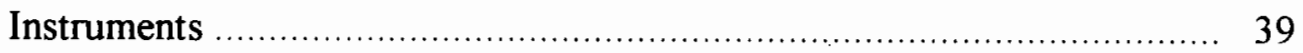

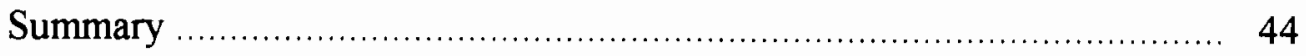


IV RESULTS

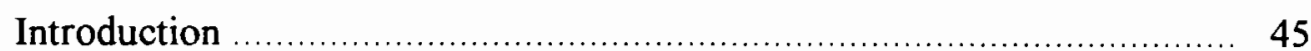

The Matrix.

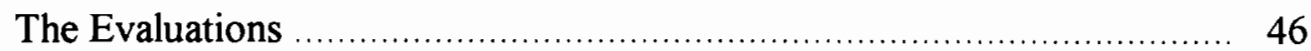

Let's Work Safely!........................................................... 46

Speaking Up At Work ....................................................... 53

ESL for Action......................................................... 58

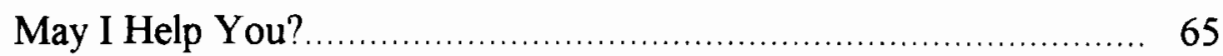

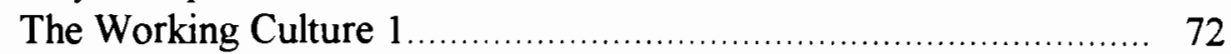

The Working Culture 2 ....................................................... 78

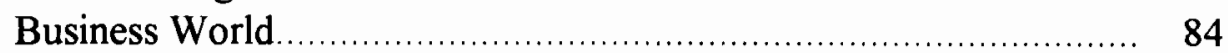

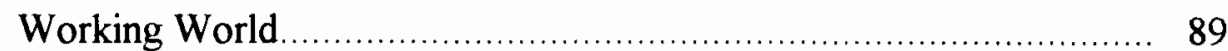

The Working Experience 1 .................................................... 94

English Works! ............................................................... 98

V DISCUSSION OF RESULTS _................................................... 104

Discussion …...................................................................... 104

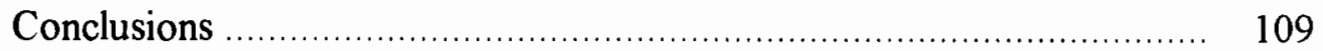

Limitations and Methodological Problems ........................................ 114

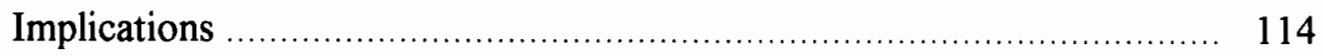

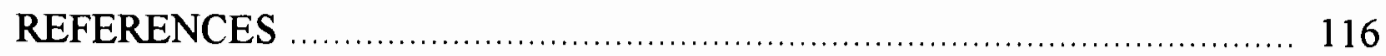

APPENDICES

A LIST OF TEXTBOOKS REVIEWED ................................. 121

B CHECKLIST FOR DESCRIPTIVE EVALUATION .................. 123

C QUESTIONS FOR IN-DEPTH EVALUATION …................... 124

D PARTIAL LIST OF EWP PUBLISHERS .............................. 126 


\section{LIST OF TABLES}

\section{TABLE}

PAGE

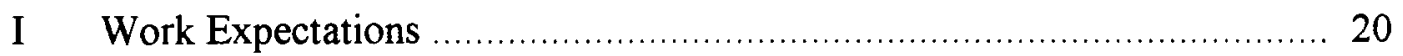

II Textbooks Used in this Study .................................................... 35

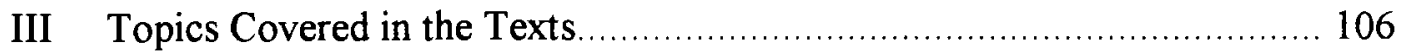

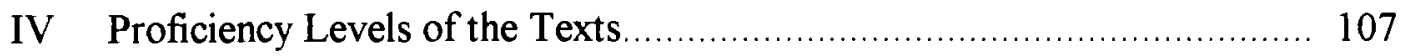

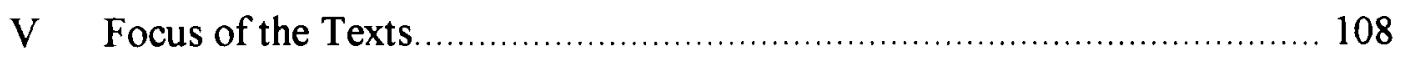

VI Organization of the Texts .................................................... 108 


\section{CHAPTER I}

\section{INTRODUCTION}

English as a Second Language (ESL) programs in the workplace are growing in number in the United States and elsewhere; likewise, many new textbooks are being written and published specifically for English in the Workplace (EWP). A need for an evaluation of these texts, with regard to current teaching methodology, the particularities of EWP, and the social implications of EWP is evident. A good EWP text can not only serve as a guide to the learners and the sponsors of the overall course content, but it can also be a resource for learners' independent practice and review. Furthermore, a good EWP text can facilitate intercultural understanding in the workplace, increase awareness of workers' rights, increase awareness of and participation in training programs for job flexibility and promotion, and finally, a good EWP textbook can develop language skills that enable the learner not simply to fit into the world of work, but to be an active participant in her/his workplace. It is the purpose of this paper to describe and evaluate currently available EWP textbooks in light of three primary concerns: the social implications of their contents, their representation of workplace relationships and culture, and their effectiveness in exploring issues of conflict and unfaimess at work. 
Prince (1984) states that an EWP course, although a language class, is by virtue of its setting, a part of the broader field of training and development. As such, the course can bear a resemblance to Prevocational ESL, which is designed for newly arrived immigrants and refugees who require some basic English before they can begin job training or job seeking; Vocational ESL (VESL), which emphasizes training for a particular trade; English for Specific Purposes (ESP), which is usually associated with medical, technical, and academic professions; or non-academic Adult ESL courses like those taught in community colleges. Other descriptions used for current EWP programs are job-specific vs. 'generic' EWP. The difference between these two types has to do with how particular the course is to an occupation or workplace. EWP programs can also be described as work-centered or worker-centered. Work-centered programs emphasize the job itself and often, a particular workplace, whereas worker-centered programs emphasize the workers themselves and their language and cultural needs both at work and outside of work. A third type of EWP program would be one that operates simply as a language class, but takes place at the work site. The design of a particular course will depend on the needs and desires of the sponsors and the learners.

EWP classes differ from traditional ESL classes in a variety of ways. To begin with, the parties involved are different. In an EWP program it is not unusual for managers, supervisors, union representatives, native English speaking employees, non-native English speaking employees, and local community education programs all to have a stake in the program. Their stake could be financial or have to do with hopes of improving work quality and communication at the work site. EWP courses also differ from traditional ESL 
courses in their scheduling. Often they do not adhere to an academic calendar or hours but are more likely to follow the flow of business at a particular work site. Thus, courses may be scheduled only during periods of time that are convenient for the company. The classes themselves may be offered before, during or after work shifts, which might be quite different from normal school hours. Finally, many of the students may be very fearful that their future work for that company depends on their success in the EWP class. Thus, it becomes important for teachers, planners, and sponsors to effectively assure workers that this is not the case.

The current goal of most language teaching is communicative competence. Bachman (1993) emphasizes that communication is a very dynamic process of nearly constant negotiation. This means that communicative competence must include much more than grammar and vocabulary. Canale and Swain (1980) propose a theoretical framework of communicative competence that includes: grammatical competence, sociolinguistic competence, and strategic competence.

In their framework, grammatical competence consists of lexical items, rules of morphology, syntax, semantics, and phonology. Sociolinguistic competence includes knowledge of two sets of rules, sociocultural and discourse. The former addresses the appropriateness of what is said and understood, and the latter emphasizes the cohesion and coherence of combinations of utterances. Strategic competence consists of the verbal and non-verbal communicative strategies that are used to compensate for breakdowns in communication, such as performance variables or insufficient communication 
Bachman's more recent framework of communicative competence differs from Canale and Swain's by attempting to illustrate how the components interact with each other and with the context. Bachman offers three components of communicative competence: language competence, strategic competence, and psychophysiological mechanisms. Bachman's category of language competence includes organizational and pragmatic ability; organization includes much of Canale and Swain's grammatical competence category (vocabulary, morphology, syntax, semantics, and phonology) and adds to it, cohesion and organization. Pragmatic competence consists of sociolinguistic ability and language functions. Bachman's second category, strategic competence, is described as the ability to implement the components of the language competence category. The third category, psychophysiological mechanisms, involves the neurological and psychological processes used in actually executing utterances. The impact of this research on language pedagogy is that recent methods aim for curricula, activities, and situations in the classroom that will elicit natural language in order to foster not only grammatical competence in a new language, but also the sociolinguistic and strategic competence necessary to be a competent speaker of the new language. Thus, activities, such as roleplays, information gap activities, and group work are utilized frequently.

Current economic forecasts for the workplace present a bleak picture and predict that workers' skills will lag behind the rapidly changing needs of the marketplace. McGroarty (1993) writes that even a conservative forecast suggests that future job openings will have higher credentials as a requirement. Moreover, she points out that skill requirements (literacy and computation especially) within particular occupations are also shifting 
upwards. Workforce 2000 reports that currently people who have not completed high school hold twelve percent of current jobs and people with four or more years of college hold twenty-two percent. It predicts that of future jobs only ten percent will be available to people who have not completed high school and thirty percent will be available to those with four or more years of college (p. 98). Gowen (1992) responds to the Workforce $\underline{2000}$ report by stating that its thesis forecasts a shortage of skilled workers just when occupations will need a more highly skilled work force. Additionally, Gowen claims, "The report blames schools, students, and workers for this problem and suggests that leadership from the private sector can solve it with minimal financial help from the government" ( $p$. $7)$.

Technology has changed not only the nature of many jobs but has eliminated many jobs as well. The use of technology has actually de-skilled some jobs by requiring broader, less specialized skills in newly created jobs (Gowen, McGroarty). Because technology changes so rapidly and changes the nature of work just as rapidly, it necessitates that workers constantly be learning and adapting (Workforce 2000). The new skills required of workers are described as ability to perform in participatory management, increased product quality, and customer satisfaction. Yet Gowen reports from the National Center on Education and the Economy, “...that 95 percent of American workplaces are not currently structured to create such a setting." Additionally, these changes and jobeliminations mean that workers will need more flexible skills and be able to change jobs several times during their working years. 
Even more interesting, Gowen reports that some analysts claim business (manufacturing and service) has done little to prepare itself or its workers for these changes. Ways of thinking about skills, knowledge, and production are the same today as they were at the beginning of the century. That is:

Tasks are broken up into small, discrete units, and employees are trained to perform these tasks with great precision. Organizational structures mirror this assembly-line approach. Companies often rely on layers of highly skilled, well-paid administrators to manage large numbers of employees with only the basic skills necessary for front-line work (p. 9)

Certainly the question of how and to what degree textbooks should be linked to the needs of the economy is of concern to many. In EWP textbooks, these concerns are addressed through claims that they will prepare immigrants to be successful, flexible, and effective participants in the workplace. But what is meant by successful, flexible, and effective participation can differ radically among employers, learners, and teachers

Increasingly, the work training goals being pushed are called "basic," "life," and "employability" skills. It is believed by many that these skills will allow for the greatest flexibility so necessary in the rapidly changing workplace. Thus, the emphasis has changed in many training and EWP programs from job-specific skills to generic, basic skills Although the emphasis has changed, the aim is still to fit people, their production, and abilities into the existing social and material conditions of the workplace rather than to change those conditions in any way (Simon, Dippo, \& Schenke, 1991).

Tollefson (1991) researched Southeast Asian refugees' immigration to the United States since the end of the Vietnam war and concludes that due to political forces of our own making, lack of competence in English for most refugees remains a barrier to jobs, 
education, and economic stability. He explains that the Office of Refugee Resettlement (part of the U.S. Department of Health of Human Services) disburses funds to refugee programs and prohibits advanced ESL study for jobs that are not entry-level positions. Thus, most refugees, regardless of their educational and occupational backgrounds, only receive enough federally sponsored ESL training to get them into low-level jobs as quickly as possible. Tollefson contends that the United States language and immigration policies are subordinate to labor policy and are actually designed to channel learners into low-level jobs. Furthermore, he writes that while ESL programs are generally regarded as being beneficial to immigrants, they are often part of “...a broad policy to channel migrants into marginal jobs in the peripheral economy that offer little security and no opportunity to gain additional language or job skills" (p. 104). Tollefson further suggests that by working such unstable jobs, immigrants provide a kind of buffer during economic periods of boom and bust.

My interest in EWP textbook evaluation is an outgrowth of my teaching experience in EWP, and prior work experience as a union organizer. In teaching EWP without the use of a textbook, I found developing my own course materials very time consuming and a heavy responsibility. Although most EWP programs are necessarily job- and companyspecific to some degree, and thus demand some materials development by the teacher, a textbook for general goals, course parameters, and practice is helpful

My experience as a union organizer has given me insight into the realities, pressures, and fears that many native and non-native English speaking workers experience in the North American workplace. Many jobs are very sensitive to changes in the nation's 
economy; thus, lay-offs, reduced work hours, and termination are not unusual.

Additionally, non-native English speaking workers, due to language and cultural misunderstanding may be more vulnerable to safety hazards, job discrimination, or harassment at work.

EWP textbooks represent a new genre of ESL materials. The demand for a welldesigned, effective, and comprehensive evaluation of currently available EWP texts is a vital one. This study examines twenty such texts for the social implications of their contents as well as the way each represents workplace culture and relationships, and how they inform about and explore issues of conflict and unfairness at work.

\section{RESEARCH QUESTIONS}

1. What textbooks specifically designed for EWP are currently available?

2. How is the workplace culture characterized and represented in the text?

- how are workplace hierarchies represented?

- how are workplace relationships represented? 
3. What knowledge does the worker/learner gain about working in the US and does this knowledge benefit her/him?

- are unions and/or employee rights addressed?

- is career planning or job advancement addressed?

- is intercultural communication facilitated?

The twenty EWP textbooks chosen for this study were designed for use in non-jobspecific EWP classes for already employed students. Additionally, only beginning and intermediate proficiency level texts were included. The evaluation process was two-fold; first a descriptive review of each text was completed. This review described the textbooks and sought to determine how well each addressed intercultural communication, unions, workers' rights, and advancement. Secondly, an in-depth review was conducted for ten of the twenty texts. The in-depth evaluations were concerned with how well the texts prepared learners to be active participants in their workplaces and unions, how well they informed about and explored issues of conflict at work, and what specific culture and linguistic points were taught.

Chapter two of this study summarizes pertinent and related research already conducted about EWP; its history, the culture of the workplace, adult learning theory, needs assessments for EWP, and textbook selection and evaluation. Chapter three describes the methodology of this study. Chapter four presents the results of both the descriptive and indepth evaluations. Finally, Chapter five, discusses these results and offers recommendations. 


\section{CHAPTER II}

\section{REVIEW OF THE LITERATURE}

This Review of the Literature begins with pertinent background information about EWP programs, including some discussion of the history of EWP, current job trends, immigration patterns, and benefits of EWP programs. Secondly, it focuses on workplace culture in the United States. Third, it addresses workplace and adult learning. Fourth, it reviews the process of conducting a needs assessment for EWP course planning. Finally, textbook selection and evaluation processes are reviewed.

\section{HISTORY OF EWP}

Work site ESL instruction really began in the United States in the early 1900 s when large numbers of immigrants were arriving and were quickly being absorbed as workers in large manufacturing companies. YMCA settlement workers initiated and pushed for ESL classes at workplaces in order to assist immigrants in coping with life in the United States and with ambitions of achieving the 'melting pot'. Korman (1965) writes, "They felt that 
love and understanding were needed as catalysts in order to make the absorption process operate smoothly" (p.151).

Settlement workers under the direction of a man named Peter Roberts of the YMCA launched specialized ESL programs at several major companies as early as 1919. Such companies included International Harvester Company in Illinois, US Steel Corporation in Indiana, and Ford Motor Company in Michigan (Korman, 1965). A conflict of interest emerged early in the planning for these classes. The managers wanted the classes to focus on factory life only, particularly safety and company policies, while the YMCA instructors wanted to include cultural and historical information about the United States as well as language for work because they believed it could lead to personal betterment, a smoother cultural adjustment, and even to citizenship. Management won this argument (Korman, 1965; Carlson, 1970).

Peter Roberts developed a curriculum and teaching technique for the YMCA teachers in conjunction with management needs and desires. He divided his curriculum into three parts--introductory, intermediate, and advanced. Few students progressed beyond the introductory level, which emphasized language for home life, factory employment, and shopping in equal parts. The intermediate level concentrated on history, geography, and civics, while preparation for citizenship was the focus of the advanced level. Roberts considered his task to be one of social service. He believed that if immigrants were left alone to fend entirely for themselves, they could become a dangerous problem, but 
through exposure to healthy American influences and example citizens (like himself) they could succeed in the United States (Korman, 1965).

The YMCA's power over curriculum planning and teaching did not last very long. Managers at Ford, US Steel, and International Harvester were quick to insist on their own priorities of discipline, safety, and company policy for curriculum content. Thus, a lesson like the following, entitled, "General" was adopted begrudgingly by the YMCA teachers at International Harvester (Korman, 1965, p. 156):

I hear the whistle. I must hurry.

I hear the five minute whistle.

It is time to go into the shop.

I take my check from the gate board and hang it on the department board.

I change my clothes and get ready to work.

The starting whistle blows.

I eat my lunch.

It is forbidden to eat until then.

The whistle blows at five minutes of starting time.

I get ready to go to work.

I work until the whistle blows to quit.

I leave my place nice and clean.

I put all my clothes in my locker.

I go home.

The mood changed dramatically in the years of World War One. The first world war inspired militant nationalism in many North Americans, which led to great fear and mistrust of foreigners who were arriving in greater numbers as war refugees. Thus, popular sentiment was to 'Americanize' newcomers as quickly and as effectively as possible. It was believed that turning foreigners into 'good' Americans was a form of nationalism and even considered a matter of national defense (Korman, 1965).

Manufacturers, caught up in the nationalistic hysteria wanted their workplace ESL 
curriculums changed in order to accommodate this new goal. Now, education leading to citizenship was a priority.

In the mid 1920s YWCA's began International Institutes in industrial cities with heavy immigrant populations. These institutes, not company sponsored, were unique in that they endeavored to ease immigrants' transition to the United States by both teaching English and American culture, and encouraging immigrants to retain their own languages and cultures (Mohl \& Betten, 1972). This was a first in immigrant education in the United States. The institutes were staffed by bi- and multilingual social workers who “...attempted to serve immigrant needs, preserve ethnic identity, and 'internationalize' the [nonimmigrant] community by promoting mutual understanding and respect among ethnic groups and between natives and newcomers" (p.276).

The Great Depression in the 1930s brought an end to most work site ESL programs and to the YWCA International Institutes due to the massive unemployment of large numbers of workers. Hardship worsened for all and North American hysteria grew as so many workers competed for limited numbers of jobs and for government relief. In fact, forced expulsion of some immigrants (mostly Mexicans) was enacted as a means of relieving the economic burden the United States faced (Mohl \& Betten, 1972). 


\section{BACKGROUND TO CURRENT EWP PROGRAMS}

Since the end of World War Two the North American economy has shifted from a manufacturing economy to a service oriented one (Auerbach \& Wallerstein, 1987; LopezValadez, 1985; Marsick, 1988). This shift has changed the nature of skilled and semiskilled occupations by requiring more sophisticated communication and language skills onthe-job. This poses obvious problems for both native and non-native speakers of English (Gowen, 1992). Auerbach and Wallerstein report that the combined effects of companies moving their manufacturing plants overseas, and increased automitization of what were once skilled jobs, have dramatically reduced the absorption of recent immigrants into the labor market.

Many of the service industry jobs available to immigrants in hospitals, hotels, restaurants, and other such places are vulnerable to fluctuations in the economy, making lay-offs, reduction in work hours, and termination frequent (McGroarty, 1993).

Workforce 2000 reports that one of the implications of this economic shift from manufacturing to service is that part-time jobs will increase. This makes the importance of transferable language and vocational skills vital. It also makes job searching skills necessary. Furnborough and Mums (1984) criticize VESL in Britain as being too short and too job-specific for transferable skills to be developed by the trainee. They argue that transferable skills must be included in VESL courses for re-training, job-seeking, and interviewing. 
When employed in North American workplaces, immigrants are often mystified by the norms, behaviors, and unwritten laws that characterize the workplace as a subculture of its own. Lopez-Valadez points out that if immigrant workers do not understand these norms, they may unwittingly violate them and suffer serious consequences, e.g., probation, termination, isolation from peers. Tollefson (1991) suggests that many refugees, although they are assured otherwise, are rightly concerned that once they accept a job, they will no longer be able to learn English. He reports that studies show that refugees rarely learn English or other skills on the job, because most of the jobs they fill require very little communication. Trebble and Wallace (1982) report that not only do immigrant workers frequently feel distant and powerless in their on-the-job interactions, but they feel remoteness from their unions as well. Unions, like workplaces, have their own hierarchies, procedures, and norms.

The ethnic composition of immigrants coming to the United States has changed over time. Lopez-Valadez states that prior to the 1960s, Europeans made up 80 percent of legal immigrants, but since the 1970s, Europeans have accounted for only 20 percent, with Latin Americans and Asians comprising the remainder. Among current immigrants, there is great diversity in their cultural, educational, and occupational backgrounds, all of which have led to varying levels of socioeconomic status in the United States (Auerbach \& Wallerstein; Lopez-Valadez). Tollefson (1991) emphasizes, however, that one's socioeconomic and educational level in one's native country does not correspond to such levels in the United States. Most refugees are poor. 
The workplace is a natural and suitable place to conduct ESL classes for a variety of reasons. For workers, the location is clearly accessible to them, and if classes can be worked into or around their normal work schedules, then they can attend without neglecting their responsibilities outside of work. For sponsors, Belfoire and Burnaby (1984); Center for Applied Linguistics (1983); and Gugliemino (1991), cite such advantages as: job-specific or related instruction to ease communication between employees and supervisors; less time wasted by relying on interpreters; less money wasted on mistakes due to incomprehension; and intercultural awareness. Additionally, Sauve (1982), in an evaluation of six companies stated that the companies volunteered that increased worker self-confidence was a major benefit of the program.

However, the amount of money management is willing to spend on worker training and education is disappointing. Gowen (1992) reports that corporate America spends between 30 and 44 billion dollars on worker training each year, but this amount is not evenly distributed across companies. A small percentage (five percent) of companies spend 27 billion dollars on education and training. Most companies spend little or nothing. Furthermore, two-thirds of the money spent on employee training is used for college educated employees. 


\section{WORKPLACE CULTURE}

"Every business--in fact, every organization has a culture" (Deal \& Kennedy, 1982, p. 4), yet practical and academic interest in, and research about the concept of workplace or organizational culture is a recent phenomenon. Hofstede (1991) states that the term 'organizational culture' first appeared in the 1960s. Moran and Harris (1987) refer to work organizations as microcultures operating within a national macroculture Workplaces have culture-- they have rules (both implicit and explicit,) values, and norms of their own. The culture of an organization influences the attitudes, values, and behaviors of the employees and thereby has a powerful effect on the workers' morale (Deal \& Kennedy; Moran \& Harris).

Several authors offer descriptions of what comprises workplace or organizational culture. Hofstede (1991) points out, however, that no standard definition of the concept exists. Deal and Kennedy have found five elements of cultural organization; they are as follows :

1. Business Environment-- The single greatest factor in shaping corporate culture. The environment in which a company operates determines what it must do to succeed.

2. Values-- The basic concepts and beliefs of an organization; the heart of corporate culture.

3. Heroes-- People who personify the organization's cultural values and as such provide tangible role models for employees to follow.

4. Rites and Rituals-- The systematic and programmed routines of day to day life in the company. Rituals are the mundane, daily routine and rites are ceremonies. 
5. Cultural Network-- The primary, but informal means of communication within an organization. It is the "carrier" of corporate values and heroic mythology. Working the network effectively is the only way to get things done or to understand what is really going on (pp. 13-15).

In Deal and Kennedy's description of workplace culture, specifically the cultural network, the word "informal" is used. In this instance it describes a means of communication that is of vital importance and "the only way to get things done or to understand what is really going on." Simon et al (1991) write that, "Working knowledge cannot be understood in abstract, general terms. It is found in particular workplaces, produced and regulated by a complex range of determinations" (p. 29). It is the informal rules that are hardest for non-native English speakers to grasp. This makes workplaces very confusing places for employees from other cultures. Simon, Dippo, and Schenke (1991) write, "Each and every task in a workplace is embedded in a particular set of social relations..." (p.27). Thus, knowing what to do and how to do it often requires much more than technical skills.

Understanding and effectively using informal communication networks is extremely difficult for employees of other cultures and those who speak a language other than English as their native language. Not understanding or successfully handling these informal aspects of workplace culture may explain employee job stagnation, isolation, dissatisfaction, and reasons for unfair termination of many employees. This, once more, points to the need for sophisticated communication and language skills in North American workplaces, and the necessity for EWP texts and classes to address this issue. 
Goldhaber (1986) explains that organizational culture is concerned with the nature of people's expectations of what it should [emphasis mine] be like to work in a particular organization. Expectations of what something should be like can vary radically from one culture to another. Moran and Harris illustrate this with a comparison of typical American work values and expectations and possible alternative viewpoints. I have excerpted those that most obviously pertain to being an employee, rather than to being a manager (which much of their book concerns itself with). The excerpted chart is as follows (pp. 76-77): 


\section{TABLE I}

Work Expectations

\section{Work Expectations of US Culture}

1. The individual can influence the future (where there is a will there is a way).

2. The individual can change and improve the environment.

3. One should effectively use one's time (time is money which can be saved or wasted)

4. A primary obligation of an employee is to the organization.

5. The employer or the employee can terminate their relationship.

6. All levels of management are open to qualified individuals.

7. Each person is expected to have an opinion and to express it freely even if his views do not agree with those of his colleagues.

8. Employees will work hard to improve their position in the company.

9. Competition stimulates high performance.

\section{Alternative Work Expectation}

1. Life follows a preordained course and human action is determined by the will of God.

2. People are intended to adjust to the physical environment rather than to alter it.

3. Schedules are important but only in relation to other priorities

4. The individual employee has a primary obligation to his family and friends.

5. Employment is for a lifetime.

6. Education and family ties are the primary vehicles for mobility.

7. Deference is to be given to persons in power or authority and to offer judgment that is not in support of the ideas of one's superior's is unthinkable.

8. Personal ambition is frowned upon.

9. Competition leads to imbalances and disharmony. 
There are a number of implications for EWP from this delineation. The first two alternative expectations suggest that EWP teachers need to recognize and be sensitive to such differing outlooks when asking students to take charge of their futures. The fifth alternative expectation conflicts with the current employment outlook. Most people will switch jobs more than once in their lives. Thus, in teaching job-searching strategies for already employed workers, teachers will need to present and explore this point. The seventh alternative, like the first two, offers a viewpoint of which teachers need to be aware. They will need to provide classroom practice in developing and expressing opinions. Lastly, points nine and ten may be helpful for employers and supervisors in that many workplaces have contests such as "employee of the month." Bosses may misperceive a resistance to contests by some immigrant workers as a lack of regard when, in fact, it is a cultural difference that causes reluctance to participate.

\section{ADULT LEARNING}

\section{Self-directed Learning}

Adult learners, by virtue of their maturity, experience, educational priorities, and time constraints (family and work responsibilities) will to some degree "direct" their own learning agendas (Hilles, 1991). Auerbach and Burgess (1985) write, "Adults must be treated as people with complex individual histories, responsibilities, needs, and goals" (p. 
477). Adult learners need the opportunity to actively participate in and take responsibility for their own learning (Hammond \& Collins, 1991; Hilles, 1991).

It is not unusual for the priorities and expectations of adult learners to conflict with those of their teachers, or in the case of an EWP program, with the sponsors. While some well-intentioned teachers or planners may have native-like proficiency and upward mobility as goals for their learners, Hilles points out that, contrary to American values, many immigrants may not share those goals. For many foreign-born workers success will be realized not by themselves as individuals, but by their children and other family members. Great sacrifices will be made by parents to enable their children to succeed in the United States. For others, the values of "moving up' and "getting ahead" may simply not be shared. Ramsey and Robyn (1992) present a view that contradicts Hilles. They state that immigrants of the 1980 s and 1990 s seem less content to simply make things better for the next generation and are much more apt to enter adult education in pursuit of skills for better paying jobs. Furthermore, they write, "Legal status for amnesty recipients and refugees is likely to encourage them to seek more skilled and higher-paying jobs and to address English language deficiencies that limit earning capacity and occupational mobility" (p.1).

\section{Critical Thinking and Learning}

Marsick (1988) writes that workplace training programs “...frequently emphasize job related knowledge and skills as if it is possible to divorce them from the rest of the 
worker's life" (p.191). She argues, however, that effective learning can only take place when this separation does not occur. Instead, both the social environment and the worker's self perception within the workplace must be taken into account. Marsick then, in discussing workplace learning, not only addresses adult learners' need to "direct" their own learning agendas within a particular class or program, but within the entire organization as well.

Shore (1992) would agree; in discussing critical learning he states that the goal of this type of pedagogy is to relate personal growth to public life. Furthermore, he writes that education that “... does not challenge the standard syllabus and conditions in society informs students that knowledge and the world are fixed and fine the way they are, with no role for students to play in transforming them, and no need for change" (p. 12).

Giroux (1983) writes, "The concept of critical theory refers to the nature of selfconsciousness, critique, and the need to develop a discourse of social transformation and emancipation..." (p. 8). Freire (1970) proposes a critical thinking approach to teaching adults which contrasts markedly with conventional adult education. He calls traditional teaching approaches "banking" systems because they entail the teacher "depositing" information into the students' minds through narration. The students become mere receptacles to be filled by the teacher. In the banking approach to education, knowledge is something given by those who consider themselves knowledgeable to those considered to know nothing (Freire, 1970). 
Freire's approach recognizes that people are conscious beings. It replaces the goal of deposit-making with dialogue about the problems of people in their relations with the world. He writes, "The students--no longer docile listeners--are now critical coinvestigators in dialogue with the teacher" (p.68). Thus, it breaks with the hierarchical patterns inherent in banking education through dialogue. The teacher and the students all become responsible for a process in which they all grow.

Critical education asks students to constantly unveil reality, but the banking approach to adult education would never ask students to critically consider reality (Freire, 1970). Giroux (1983) writes, "Rather than celebrating objectivity and consensus, teachers must place the notions of critique and conflict at the center of their pedagogical models...Critique must become a vital pedagogical tool" (p.62).

Reflection plays a crucial role in critical learning. Marsick and Watkins (1993) write that critical reflection involves critical thinking in the realm of interpersonal interaction. Hammond and Collins (1991) write:

Reflection often results in learners being more aware of their feelings, motives, and of themselves in their social contexts. The resulting self-awareness promotes personal growth, and the external linking with the social context promotes critical awareness and may lead to subsequent social action. (p. 166)

While acknowledging that there are circumstances when it is necessary and appropriate, Marsick (1988) rejects the behavioral, competency-based workplace training model. She is in favor of developing a new model that would emphasize critical reflection skills for workplace learning. By developing critical reflection skills, Marsick contends, workers will be able to exploit informal or on-the-job opportunities for learning. Critical 
reflective learners/workers will probe below the workplace surface for underlying causes, self-directed understanding, and problem-solving. Marsick writes that training and development programs are mere delivery systems but, "By contrast, learning is the way in which individuals or groups acquire, interpret, reorganize, change or assimilate a related cluster of information, skills and feelings. It is also primary to the way in which people construct meaning in their personal and shared organizational lives" (p.192). It is important to identify whether or not EWP textbooks designed for adult learners actively promote self-direction, critical awareness, dialogue, and critical reflection.

Workplace learning and training often avoids the issue of pay. Simon et al (1991) believe this omission gets justified by many because pay is considered a private matter in the United States, and because talk of pay with low-level employees, and students headed for low-level jobs only adds insult to injury. Simon et al, however, argue that pay must be directly dealt with in work education classes, since workers must make frequent decisions about jobs on the basis of what they understand to be fair pay. Critical education about pay would not only entail an exploration of the ways of getting paid (e.g. piece-work, wages, salaries), but would also include issues of social and economic justice, such as labor divisions along gender, race, and class lines.

\section{Language Teaching Approaches for Adults}

One of the first considerations when planning a language course is whether to teach structures or functions. Structural approaches emphasize language form (grammar) while 
functional approaches emphasize behavior with language. Since the advent of communicative language competence theory and research, most approaches currently used aim for communicative competence. The functional approach has been widely used in adult ESL since the 1970s and often takes the form of a functional/notional concept of language description. Hutchinson and Waters (1987) explain that functions are associated with social behavior and represent intention, for example, advising, warning, threatening, describing, etc. Notions reflect the way in which the human mind thinks. Notions are categories by which reality is divided, such as time, frequency, duration, gender, number, location, quantity, and quality. They write, "A functional syllabus appears to be focused on language in use, in contrast to the structural syllabus, which shows only form" (p. 32).

An approach borrowed from adult education is Competency-based Education (CBE). Hammond and Collins (1991) define CBE as "a learner-centered model which arranges learning and teaching around the actual competencies a practitioner needs to function effectively in the real world" (p. 97). The CBE syllabus is performance oriented; it is outcome, or competency-based rather than subject-matter based. Since students continue until they demonstrate mastery of competency, accountability is provided for teachers and program planners. Additionally, this makes it an individualized approach (Hammond \& Collins)

A final category, humanistic, holistic approaches, include Freire's problem-posing approach among others. In problem-posing, it is through challenging assumptions, critically reflecting upon issues, and developing strategies to change the status quo that learning takes place. Freire writes: 
Students, as they are increasingly posed with problems relating to themselves in the world and with the world, will feel increasingly challenged and obliged to respond to that challenge. Because they apprehend the challenge as interrelated to others problems within a total context, not as a theoretical question, the resulting comprehension tends to be increasingly critical and thus constantly less alienated. (1970, p.69)

\section{EWP NEEDS ASSESSMENT}

Needs assessments are crucial to EWP programs as they determine both the sponsor's expectations, needs, and desires as well as the learners'. This information is then analyzed by course planners for curriculum design. Many researchers (Belfiore \& Burnaby, 1984; Bell, 1982; Center for Applied Linguistics, 1983; Hutchinson \& Waters, 1987; Prince, 1984; and West, 1984) have devised similar procedures for conducting the needs assessment. The process consists of five steps, beginning with a tour of the work site. This tour serves several purposes. First, it gives the EWP planner a general "feel" for that particular workplace; secondly, it allows him/her a chance to meet key personnel; and it offers the EWP planner a glimpse of the pace of work, the work conditions, and the language used during the work shift.

The next step is to interview managers, supervisors, prospective learners and their coworkers. The aim of these interviews is to learn about specific language used on the job, and to elicit examples of communication problems that have occurred due to language or cultural misunderstanding. Interviews with native English speaking co-workers especially are a good source for information about the social language that occurs at the work site. 
Belfiore and Burnaby state that social language comprises a considerable part of the communication in most jobs.

The third step in the needs assessment is observation. Ideally, the EWP planner would actually work a shift at the site as Bell (1982) recommends, but when that is not possible, observing or "trailing" a particular employee during a shift is sufficient. At this stage, the EWP planner learns how various tasks of the job are done, and learns what relations between departments are necessary, in order to fully understand the learners' jobs, and their frustrations and pressures while working.

The fourth step is to assess the language proficiency levels of prospective learners and to group them accordingly. This can be done through formal testing of the participants, but as Belfiore and Burnaby caution, in a workplace setting, this can be extremely intimidating for learners who may fear that test results would be used against them. Also, time constraints frequently prevent EWP planners from conducting formal testing. Informal interviews can be used to assess oral proficiency levels and similarly informal reading samples can be used to determine literacy levels of the learners.

The final step in the needs assessment is to analyze all of this data. The EWP planner looks for common problems and issues determined from the interview and observation stages and then relates them to the results of the language assessment and uses these to design a curriculum. The needs assessment process can be a long and complicated one. McGroarty writes, “...even the preliminary phases of planning workplace instruction demand new sorts of knowledge, an expanded ability to appreciate the concerns of other parties, and a willingness to adapt and compromise..." (p.92). 
Prince (1984) divides the needs assessment into two types, a work-oriented assessment and a worker-oriented assessment. He suggests that both types be used for targeting needs. A work-oriented assessment collects data about job and company procedures, standards, policies, forms, etc. This assessment then, is job and company-specific. A worker-oriented assessment collects data pertaining to generic job variables, and transferable language and vocational skills. Hutchinson and Waters (1987) pose similar categories, calling them objective and subjective views of needs. They state that these two views will undoubtedly reveal some conflict, and advise course planners to bear this in mind in writing the curriculum.

\section{TEXTBOOK SELECTION AND EVALUATION}

Many researchers (Bruder, 1978; Hutchinson \& Waters, 1987; and Skierso, 1991) have devised a variety of checklists, criteria, and procedures for selecting and evaluating course textbooks. All of these include targeting the audience, surveying available texts, analyzing the texts and evaluating or judging them.

Skierso suggests collecting preliminary data before the evaluation process begins. This preliminary data would include background information about the students, e.g., their English level, reason for studying English, age, background information about the institution or sponsor; and background information about the teacher. As Hutchinson and 
Waters point out, for the EWP or ESP planner, this information would come directly from the needs assessment.

The selection or evaluation process begins with a survey of available texts and a cursory look at their contents. This entails reading the introduction for comments by the author about the aims of the text and methodology or theory the text endorses; skimming the table of contents to get a sense of topics or structures covered and their organization within the text; and looking at illustrations or photographs included in the text. Bruder suggests that at this point some texts can be excluded from further consideration if they are deemed inappropriate. Skierso, and Hutchinson and Waters, on the other hand, caution against making that decision too hastily and recommend recording these initial impressions and setting the texts aside for later analysis.

Skierso and Bruder both offer extensive checklists for the analysis of the texts to determine vocabulary, structural, functional, and cultural text contents. The checklists would then be tallied by category and a final judgment would be made based on these results and the preliminary data collected.

Hutchinson and Waters have developed an exhaustive evaluation process geared for matching a text with a particular ESP or EWP course. In this case, questions are answered subjectively (based on the needs assessment) and objectively (based on the text's contents) concurrently. Once these questions are answered, the evaluator can determine how well a text matches the particular course either impressionistically or numerically. Finally, as no text will be a perfect match, they recommend evaluators and planners take 
into consideration which mismatched areas will be easier to remedy in their particular situations.

Damen (1987) has developed a method for evaluating the cultural content of a language text. She explains that evaluation of cultural content is vital since most new textbooks emphasize culture due to current emphasis on cultural as well as linguistic competence (communicative competence). Damen not only believes that texts should be evaluated for their cultural content as well as their language content, but that the two should be of equal consideration. She uses the metaphor of a scale and suggests that language and cultural elements of texts are the weights. It is the evaluator's job to balance the scale by weighing the elements according to the basis of choice (context, client, communicator, and text.)

Damen offers three cultural elements or weights: content, method, and perspectives. Of content, she warns that frequently the cultural weight of a text is hidden or covert. Thus, she says, the evaluator must step outside of his/her own culture in order to evaluate the text's cultural content effectively. She claims there are two general categories for methods of presenting cultural content. The first promotes understanding of a new culture, the second attempts to produce appropriate behavior within a new culture. A final important consideration is whether the presentation of cultural information is "realistic" or "idealized." 


\section{SUMMARY}

EWP has evolved from the broader fields of TESOL and training and development, based on the shift in the American economy from manufacturing to service industries. This shift has created a need for increased workplace communication skills, even for low level, low paying jobs. For many immigrants who are balancing the demands of employment and family responsibilities, EWP programs offer a much needed and desired opportunity to continue language learning, and to develop workplace and vocational skills.

The pendulum has swung in EWP from strictly work-centered curriculums in the early 1900s to citizenship-based courses in the wake of World War One to current approaches that aim to conform to economically determined workplace needs by teaching broader, more flexible language skills. Additionally, current approaches appear to take workplace culture into consideration by emphasizing communication and interaction. They also draw on adult education theory, thereby emphasizing real life situations and past life experiences as starting points for learners.

As a new and still emerging field, textbooks designed particularly for EWP programs are becoming increasingly available to EWP practitioners. Textbooks can be a great resource for learners, and can spare teachers the time and responsibility of having to develop all of the course materials themselves. But a poorly designed textbook, or a mismatched one can be an enormous waste of money and a source of great frustration for teachers and learners. What is more, educators must be aware that the textbook choices 
they make reflect their view of learning, the larger social context, and the students' place in society. A review of currently available EWP texts and a thorough evaluation of them is much needed. This should not only help others in the selection process, but may also serve to inform TESOL professionals, textbook writers, and publishers of concerns in EWP. 


\section{CHAPTER III}

\section{METHOD}

This study is a survey and evaluation of current EWP textbooks. Twenty textbooks were surveyed and evaluated descriptively. Ten texts were chosen from the twenty to be evaluated critically. Of the twenty texts chosen for this study, some were found by perusing publishers' catalogues, and by browsing colleagues' textbook collections. Most of the textbooks, however, were borrowed from my advisor. Although I requested review copies of texts from publishers, I learned that publishing houses do not send review copies of their textbooks to individuals. Appendix D offers a partial list of EWP textbook publishers. The oldest text in this study was published in 1983, and the newest in 1995 .

In publishers' catalogues, checking under the headings of "Vocational English," “Business English", "English For Specific Purposes", and "English For The Workplace” was the most helpful. When browsing textbook collections, I paid attention to any book with a reference to work, business or employment and English in its title or subtitle. Several textbooks in this survey were designed for use with both non-native and native speakers of English. 
This study was limited to textbooks designed for learners at the beginning and intermediate proficiency levels. Appendix A lists the textbooks used for this study. Originally, I was interested in evaluating texts that were both job-specific, English for Specific Purposes (ESP) and generic EWP; however, most of the ESP texts found were at advanced levels and thus, ESP texts were eliminated from this study. It is also true that a good number of the ESP textbooks I came across were over fifteen years old. Most of the Business English textbooks were also at advanced levels, but three, at the intermediate level, were included in this study. Additionally, this study was limited to texts that were designed for employed learners rather than prevocational learners.

\section{TABLE II}

Textbooks Selected for this Study

1. Let's Work Safely!

2. Speaking Up At Work

3. ESL For Action

4. May I Help You?

5. The Working Culture 1

6. The Working Culture 2

7. Business World

8. English Works!

9. The Working World

10.The Working Experience 1
11. The Working Experience 2

12. Your First Job

13. Business Venture 1

14. Business Objectives

15. Working In English 1

16. Working In English 2

17. Day By Day

18. Workskills 1

19. Workskills 2

20. Joblines

These twenty textbooks were selected for a number of reasons. First, the texts for this study represent a variety of themes, occupational focuses, and teaching approaches. Also, since a majority of EWP textbooks at the beginning and intermediate levels target speaking and listening skills, it was important to include some EWP reading texts in this 
survey. Several texts could fit into more than one of the representative categories, but all were placed in only one category except for The Working World listed here in three categories.

Therefore, based on descriptions of the textbooks in publishers' catalogues and on book jackets, the texts were selected for the following reasons. The Working Experience $1 \& 2$, Working World, Working In English $1 \& 2$, and Joblines were all chosen for their reading emphasis. The Working Culture Book 1 and Working World were chosen for their cultural themes. The occupational focuses of May I Help You? (service industry), Your First Job (manufacturing), and Business World, Business Venture 1, Business Objectives (business) were the reason for their selection. The Working Culture Book 2 and Working World were chosen for their theme of advancement. English Works!, Workskills $1 \& 2$, and Day By Day were chosen because of their recent publication, and Speaking Up At Work for its popularity. Finally, Let's Work Safely! was selected for its safety focus, and ESL For Action for its unique teaching approach (Problem-posing).

\section{GENERAL DESIGN OF THE STUDY}

The results of the descriptive evaluation appear as a matrix. It is hoped that the matrix will provide an easy, efficient way for others to find out about and compare current EWP texts. Considerations of this descriptive evaluation include: facts about the text (publisher, author, etc.); information about the goals and contents of the text given in the 
introduction, preface, and table of contents; additional teaching aides available for the text; and answers to questions about how well cultural and workplace information was addressed in the text. In order to evaluate and describe the books efficiently and consistently, I developed a checklist for the descriptive evaluation. Specifically, the checklist concerned facts about the text--author, publisher, price, methodology (if stated), topics covered, organization, and level. Additionally, the checklist sought to determine if the text represented various culture groups, and if and how successfully it addressed intercultural communication, unions, and job advancement.

Results of the in-depth evaluations appear as detailed, evaluative book reviews. After consulting many checklists and criteria for textbook evaluation, again, I created my own list of questions for evaluation. This evaluation considered the linguistic items included in the text, specific cultural information included, how workplace relationships and hierarchies were characterized, whether or not the text encouraged the learner to become a participant in the workplace, and what actions should be taken if the learner felt he/she had been treated unfairly or unlawfully.

In addition to answering the questions above, there were other criteria I believed made a good EWP textbook. These are as follows:

- realistic workplace situations depicted and explored

- informal as well as formal registers modeled

- many kinds of workplace relationships represented

- non-verbal communication covered

- workplace shown as being culturally diverse

- work values explored cross-culturally

- intercultural communication facilitated

- employees prepared to be active participants in their workplace and/or union 
The first four criteria fall into a category of communicative language competence, particularly Canale and Swain's (1980) components of sociolinguistic and strategic competence. The representation of realistic situations, informal and formal registers, various work relationships, and non-verbal communication lend themselves to fostering students' understanding of sociocultural and discourse rules. Additionally, these can help students develop strategic competence. Canale and Swain write that the coping strategies necessary for strategic competence are most often acquired through real life communication. Textbooks that meet the first four criteria can create realistic communication in the classroom.

The next three criteria: portrayal of a culturally diverse workplace, cross-cultural exploration of work values, and facilitation of intercultural communication comprise a cultural competence category. Texts that meet these criteria can ease learners' and workers' acculturation by increasing awareness of their own cultures, as well as exploring differences that may result in misunderstanding or conflict at work. Inclusion of such cultural information can also help learners to view themselves as culture learners as well as language learners.

Finally, the last criterion, preparing workers to participate actively in the workplace, combined with two already mentioned criteria: exploring work values cross-culturally, and representing various work relationships, form a workplace competence category. Deal and Kennedy (1982) include values and the informal network as two of five elements of workplace culture. Textbooks that explore work values cross-culturally recognize both 
the importance of values at work and the fact that values can vary across cultures. Texts that prepare learners to be active participants not only prepare them to be leaders at work, but also help them to be a part of the network--the primary, but informal means of giving and receiving vital information at work (Deal \& Kennedy). Additionally, the representation of many workplace relationships fosters successful participation in the network too.

\section{INSTRUMENTS}

The checklist for the descriptive evaluations (see Appendix B for a copy of the checklist) begins with a background section in which the title, publisher, year of publication, author, price (for 1995), and level are listed. Most of the textbooks stated their level, but three did not. In those cases, it was indicated that the level was not given and I offered my opinion as to its level. Additional background information gleaned from the texts was a list of the topics it covered, its organization, whether or not it was workcentered or worker-centered, and its methodology. The topics were usually taken directly from the table of contents and lesson sub-titles. In terms of organization, of most interest was whether the chapters suggested a topical/functional, theme-based, problem-posing, topical or competency-based syllabus. None of the texts explicitly stated their methodology and since most materials published within the last 15 years use a variety of methods geared toward teachers using the communicative approach, I found the methodology category to be of little use. Finally, any additional teaching aids available 
with the texts were included as background information. Additional teaching aids looked for included teacher's manuals, audio tapes, video tapes, glossaries, and indexes.

Secondly, the descriptive evaluation included a section on workplace and cultural concerns. For these seven questions, a simple "yes" or "no" was not an informative enough response, because the degree to which the texts did or did not address these issues varied greatly. Therefore, answers were rated on a scale of 1 to 5 with 5 being the most true. Thus, $5=$ very well covered, $4=$ well covered, $3=$ adequately covered, $2=$ poorly covered, $1=$ very poorly covered or not covered at all. The seven questions are as follows:

1. Is the workplace depicted as being culturally diverse?

2. Is cross-cultural communication addressed?

3. Are unions addressed?

4. Are job advancement and job hunting covered?

5. Is workplace training addressed?

6. Is information provided about employee rights?

7. Is information given about employee benefits?

To answer the first question, I noted whether or not the illustrations and photographs depicted people of various races and cultures and whether or not such people were depicted as being both bosses and workers. For cross-cultural communication, exercises and discussions that asked students to explore aspects of their own culture and compare them to American culture were looked for. For question number three I noted not only whether or not unions were described, but also if unionization was explored through exercises and discussions. 
For the fourth and fifth questions, sections that presented information about job changing, job searching, performance reviews, and that encouraged self-evaluations and goal setting were looked for. Question six was answered by reading information provided in the texts about workers' rights and determining whether or not it was clearly stated and thoroughly explored through discussion and case studies or scenarios. Lastly, for question seven, I looked for information about the kinds of benefits that can be offered to employees and the kinds of jobs that may include various benefits.

The ten questions for the in-depth evaluations served as a guideline and helped to keep examples from the texts organized for evaluation later (see Appendix $\mathrm{C}$ for a copy of the checklist). Information from both the descriptive and in-depth evaluation checklists was included in the reviews. The in-depth reviews were each shaped by the text itself and therefore include additional information not found from either checklist.

\section{Questions for the In-depth Evaluation}

1. What cultural and workplace situations are depicted in the text?

2. What kind of language is represented?

3. How are workplace relationships depicted?

4. How are workplace hierarchies represented?

5. How are unions characterized?

6. What cultural attitudes about time are addressed?

7. What topics for conversation are covered?

8. How is intercultural communication facilitated by this text?

9. How does the text encourage the learner to become an active participant in his/her workplace?

10. How does the text address what a worker should do if he/she feels he/she has been a victim of harassment, discrimination, or otherwise treated unfairly?

To answer the first question I searched for examples in each text of cultural and workplace situations and issues, such as interpreting gestures and facial expressions, 
calling in sick, coping with rudeness, making friends, attitudes about work, attitudes about health and safety on the job, and much more. The question about the kind of language represented in the texts sought examples of both formal and informal English. In the United States formal language is normally used for job interviews, but informal language for day to day interactions at work. Additionally, I looked for lessons that introduced common idioms, slang, and jargon.

For questions three and four, dialogues and role-plays between workers and their bosses and among workers were sought. Examples of workers responding to discipline and criticism, unfair treatment, requests, rudeness, and humor from their employers were looked for. Examples of employees apologizing to their bosses and insisting on something to their bosses were also noted. Relationships among employees are important; thus I looked for examples of their interactions. Models of social communication, conflicts and resolution of conflicts, friendship, and unity among both non-native and native speakers of English were also searched for.

In question number five, I wanted to determine how the textbooks characterized unions; that is, did they simply offer a brief overview of what one is and present some key terms, or did they actually explore unionization? Clear descriptions of unions, the role member participation plays in them, and contract negotiations were sought. Also, exercises that would spark discussion about unions and comparisons between union and non-union jobs were looked for. 
Question number six asks about cultural attitudes about time. Here, lessons, dialogues, and role-plays that dealt with issues of tardiness, absenteeism, and work speed were sought. To answer question seven, I looked for examples of social conversation--how conversations begin and end, and what kinds of things are appropriate to talk about with whom. Also, the texts were examined for ways they might encourage students to strike up conversations with others outside of the classroom.

For answers to question number eight, lessons and activities that dealt with the difficulties people face when living in a new culture, and misunderstandings that can arise were sought. Additionally, cross-cultural comparisons and affirmations of students' native cultures and languages were looked for. Question nine asks how the texts encourage learners to be active participants in their workplaces. Here, I looked for activities that asked students to do something outside of the classroom--begin a conversation, make an appointment with the boss, attend a union meeting, etc. Additionally models of reporting a health and safety concern, and examples of worker health and safety committees were looked for.

Finally, to answer question number ten, I looked not only for clearly presented information about workers' rights, but for information about a worker's recourse if he/she has been treated unfairly. Thus, lessons introducing wage and overtime laws, health and safety laws, the Occupational Safety and Health Administration (OSHA), discrimination laws, sexual harassment laws, and laws protecting strikers and union drives were sought. 
Besides presentation of this information, I looked for the equally important inclusion of activities and discussions of real life scenarios and experiences regarding these rights.

\section{SUMMARY}

The purpose for developing a matrix from the descriptive evaluations was to provide a convenient and quick reference chart for other EWP teachers and planners. It should help others in the selection process of textbooks for their programs by offering an overview of currently available EWP textbooks. The in-depth evaluations, besides providing more information about the texts, also offer a critical review of each of them. This should help EWP teachers in selecting texts and may also inform publishers and textbook writers of vital concerns, issues, and responsibilities in EWP. 


\section{CHAPTER IV}

\section{RESULTS}

In this chapter the results of both the descriptive and in-depth evaluations are reported. The descriptive evaluations are displayed in the form of a matrix delineating most of the information from the descriptive evaluation checklist. The ten in-depth evaluations appear as book reviews.

The ten books selected for the in-depth evaluations were: Let's Work Safely, Speaking Up at Work, ESL for Action, May I Help You, The Working Culture Book 1, The Working Culture Book 2, Business World, Working World, The Working Experience 1, and English Works. These ten were chosen for the variety of their emphases, and approaches. Let's Work Safely focuses on safety, May I Help You on service occupations, cross-cultural communication is the focus of The Working Culture Book 1, advancement of The Working Culture Book 2, and Business World is a business English text. Working World and The Working Experience 1 are both reading texts. Speaking

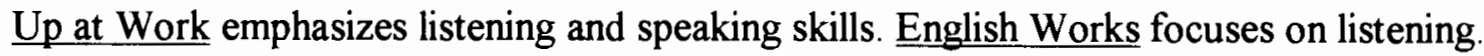
ESL for Action uses the problem-posing teaching approach. 
Let's Work Safely! English Language Skills for Safety in the Workplace

Let's Work Safely! by Linda Mrowicki, just as the title reflects, is an EWP textbook that emphasizes workplace safety. The author suggests that the text be used at the highbeginning and intermediate levels. The text is primarily a speaking text, but does include some reading and writing. This text addresses health and safety concerns in a variety of work sites and occupations, including: vocational schools (machine operator and carpenter), hotels (housekeeper and food preparer), factory workers (sorter, forklift driver, welder, assembler), and maintenance workers. Many of the safety concepts introduced in this text are general, but the situations in which they are presented focus on particular occupations.

Let's Work Safely! focuses on work safety only. It is work-centered and competencybased. No affective factors, such as embarrassment, fear, or fatigue, are included in connection with workplace safety. The language emphases include insisting, reporting and interpreting signs.

At the beginning of the text, the author provides a course outline of the text's 19 lessons. For each lesson functional competencies, grammatical structures, vocabulary, and a safety topic are targeted. The competencies include such things as comprehending and giving instructions about safety, requesting and insisting on safety wear, giving and 
accepting advice politely, reporting accidents, and making suggestions for preventing accidents.

The text opens with startling and sobering statistics about worker injuries and deaths in the United States during a three year period. These facts emphasize the importance of safety on the job. The statistics are presented as a simple reading passage: " $1,900,000$ workers were hurt in 1984. 11,700 workers died on the job. WORKERS MUST BE CAREFUL"(p.2).

Language is presented and practiced in short, simple reading passages, labeling of pictures, dialogues, and role-plays. The reading passages are followed by comprehension questions. Pictures are widely used throughout this text; some are examples of safety signs in workplaces and others are illustrations of unsafe conditions which students are asked to explain. The dialogues model the language points and competencies for the lesson. For example, this dialogue between two co-workers, illustrates a non-native English speaker insisting on proper safety wear (p.30):

Co-worker: Bee, carry those boxes outside for me, would you?

Bee: $\quad$ OK, but I need a hard hat.

Co-worker: Why?

Bee: $\quad$ A box might fall off the forklift. I want to be safe.

Co-worker: It'll be OK. I don't think you need a hard hat.

Bee: $\quad$ No, I really need one. It's better safe than sorry.

Co-worker: Well, there's probably one in the office.

Bee: $\quad$ OK, I'll go get it. I'll be back in a minute.

Another emphasis of the text is the interpretation of signs. Abundant use of pictures is an exceptional feature of this text. This is particularly relevant in that many workplaces 
use posters to convey safety hazards and warnings. Mrowicki makes use of real safety posters and signs, adding greatly to the authenticity of the text. In many exercises, students are asked to interpret the meaning of a poster/sign orally and in writing. Posters often work on an almost subliminal level for native-English speaking employees, but for non-native English speaking employees, many posters may not be clear. For example, a picture of a string around the finger to signify "don't forget" may not be meaningful without explanation.

Role-plays offer students the least controlled means to practice the language and competencies presented in the lesson. They generally come at the end of the lessons. For example these three role-plays illustrate a worker reporting an unsafe condition to three different people, a manager, a supervisor, and a shop steward (p. 77):

1. A worker is talking to the manager:

A

You are the worker. You tell the manager that you would like to report an unsafe condition. You describe the hazard and explain what kind of accident could happen. Then you make a suggestion.

2. A worker is talking to a supervisor:

A

You are a worker. You want to report an unsafe condition. You explain what kind of accident could happen and you make a suggestion.
B You are the manger. You are interested in learning about unsafe conditions. You ask for a suggestion.
B

You are the supervisor. You want to find out about unsafe conditions. You listen to the worker. You tell the worker that you will talk to the manager. 
3. A worker is talking to the shop steward:

A

You are the worker. You want to describe an unsafe condition. You ask what the shop steward can do.
B

You are the shop steward. You listen to the worker. You ask the worker to fill out a form. You will give the form to the manger and talk to the manager about the unsafe condition. You will get back to the worker next week.

Relationships among workers come across as being egalitarian. Some illustrations and dialogues depict interaction between native English speaking employees and non-native English speaking employees as in the "insisting dialogue" between Bee and a co-worker. The relationships between workers and their bosses are presented in an ambiguous manner; that is, very little response is offered in this text by bosses toward their employees, which leaves the role-play or dialogue unresolved. In interactions between workers, a resolution is usually depicted. For example, in the above three role-plays, when the worker reports an unsafe condition to the manager, the manager asks for a suggestion and ends it at that. When the worker reports to the supervisor, he/she is told that the supervisor will tell the manager about it. When the worker reports to the shop steward, however, the steward gives him/her a form to fill out, tells him/her that the steward will talk to the manager about it, and tells the worker when the steward will get back to him/her about the problem.

Again, a dialogue in which a worker insists to his/her supervisor that safety wear is needed ends without resolution. This is very different from the earlier insisting dialogue between Bee and his co-worker (p. 13): 
Worker: I need some ear plugs.

Supervisor: Why?

Worker: There's a lot of noise.

Supervisor: It's OK.

Worker: No, I really need ear plugs.

Additionally, dialogues depicting workers making suggestions to bosses and shop stewards about safety hazards are included. In most cases the dialogue ends with the boss telling the employee he/she will take the matter into consideration. p.77 and p.72:

To supervisor p. 77 :

Worker: There's a lot of noise. I think it would be safer, if we had ear plugs. Supervisor: OK. I'll look into it.

To shop steward p. 72:

Johanis: Mike, can you come here a minute?

Shop Steward: Sure. Be right there.

Johanis: It's pretty dark in here. I don't think it's safe to operate the machines here.

Shop Steward: Do you have a suggestion?

Johanis: $\quad$ Yes, I think we need another ceiling light. It would be safer if we had more light.

Shop Steward: OK, I'll look into it. You could be right. I'll talk to the manager today and get back to you this afternoon. Thanks for the suggestion.

It is interesting that both in this dialogue and in the role-play, the shop steward gives the employee a specific time when he/she will get back to him/her with a response. This is quite different from the responses given by the managers and supervisors, who receive the suggestions with thanks, but offer no follow up.

Two things stand out about this text. The first is Mrowicki's frequent use of posters, signs, and illustrations. The second is the emphasis she puts on workers insisting on their own safety. This is extremely important and the practice provided by the models and role- 
plays is very helpful to students and surely boosts their confidence in expressing themselves outside of the classroom.

Overall, this is a fair text for teaching basic safety and the language needed to understand and express oneself in regards to basic safety. But it is a poor choice for examining and exploring safety in a context broader than the personal. The careful organization and clear presentation of the lessons are helpful to both teachers and students. It is also important that the text depicts many types of work. This can help students who are unfamiliar with the American workplace to catch a glimpse of a variety of occupations. I imagine that it would be useful when used as a supplemental text in an EWP course. Teachers would need to incorporate other materials to address the affective factors associated with workplace safety and everything else in the workplace besides safety.

There are several problems within the text of a fairly serious nature. First, it is a great shortcoming that this text offers no advice, language, or practice in what to do if an employee's boss does not agree with him/her that something is indeed a safety concern, or agrees, but does not act. Because health and safety hazards are named by human beings, there are frequently disagreements (Simon, Dippo, Schenke, 1991). In Mrowicki's text, the official naming of hazards is reserved for the managers only; even the supervisors must defer to management for the naming of a hazard.

Simon et al suggest that there are three kinds of solutions for health and safety problems in the workplace: technical (changes in equipment), administrative (changes in 
schedules, breaks, job rotation), and personal (things workers can do). All of the solutions presented in this text are personal, other types of solutions are not even presented as possibilities; thus the message is that workers are the sole bearers of responsibility for their health and safety. This is a misleading and dangerous message. Students need to be aware of other types of solutions. Furthermore, Mrowicki does not depict collective responsibility for health and safety. Many workplaces now have employee committees in charge of health and safety issues. The addition of examples of worker-initiated changes would have strengthened the text.

Another shortcoming is that no affective variables are dealt with in this text. Many workers feel embarrassment or shame if they have been injured. They may also feel afraid of losing their jobs. These ought to have been addressed. Also, many employees are embarrassed or afraid of making suggestions to people in higher positions than themselves because they fear they will be seen as dissatisfied and critical of their workplace.

The only affective variable addressed in this text was inattentiveness. The text simply advised that workers stay alert (p.39). In a role-play on p. 40 , students are shown a picture of a worker looking out the window while operating a machine. In the role-play, both students are workers, and one advises the other about not looking out the window. The topic of inattentiveness deserves deeper attention than that. Causes such as fatigue, stress, and breaks need attention. This is particularly true for night shift workers and people who work more than one job. 
In conclusion, Let's Work Safely is a disappointing text. Because it presents only personal solutions to safety issues in the workplace, it could seriously mislead workers. Students need to be aware of other kinds of solutions (technical and administrative). They also need to know how to act collectively as well as individually to push for and see effective changes of all types made for their safety. However, there were no other texts devoted to generic workplace safety found. It is an important topic, and one that every worker should feel capable of understanding and expressing him/herself about.

\section{Speaking Up At Work}

The goal of Speaking Up at Work by Catherine Robinson and Jenise Rowekamp, is to help adults with limited English proficiency be successful employees. Thus, it emphasizes skills needed to maintain employment and to advance on the job. The preface states that although the book was designed for use with non-native speakers of English, it can and has been used with native speakers of English as well. A recommended proficiency level is not stated, but I believe this text could be used with low-intermediate to intermediate students. The text focuses on speaking and listening skills and language competencies for work.

There are 11 units in this text, each divided into three sections. The three sections each deal with different kinds of work and language competencies. These are (p. ix): 
Section 1: Cultural information for improved social interaction

Topics include: making small talk, phoning in sick, apologizing, and describing past work experience

Section 2: Language and culture for training and increased worker flexibility Topics include: asking for clarification, giving and receiving directions, and discussing problems.

Section 3: Understanding job policies and procedures

Topics include: understanding work schedules, safety rules, taxes, benefits, and unions.

The organization of Speaking Up at Work is unusual and well done. Because the units themselves are not topically organized (but the three sections within the unit are), it allows a variety of unrelated topics to be addressed in each unit. For instance, section three of each unit deals with information to help workers understand job policies and procedures; many of this section's topics (understanding paychecks, understanding health insurance, etc.) require that some difficult, wordy information be presented. If many of these topics had been lumped together in a theme-based syllabus, such a unit might end up being long, perplexing, and dull. Thus, this organization allows for diversity within units and emphasizes the integrated nature of these skills in real life. Another strength of this text is that most lessons include an activity called "Using What You've Learned," in which students are required to use learned competencies outside of class.

Section one (cultural information for improving social interactions) of unit six contains a lesson called "Apologizing." There are five role-plays for students to practice apologies, all of which depict workers apologizing to supervisors, or workers apologizing to one another, but never a supervisor apologizing to an employee. The example below 
fails to acknowledge an important issue--work load. Why was the worker in such a hurry and unable to a good a job? This is an important consideration. Unfair demands on workers' time can prevent them from doing tasks properly and can certainly influence their need and desire to apologize (p. 96):

Supervisor

You asked a worker to clean some tables, but he didn't do a good job.
Worker

You were supposed to clean some tables. You were in a hurry and didn't do a good job.

In section one of the first unit, the cultural entry given below appears. The purpose of these "In The US" exercises is to prompt discussion of North American culture. In this example, students are asked to interpret what North Americans think of their co-worker (p. 5):

Vone is a very hard worker. She is always on time. She comes to work and goes right to her desk without speaking to anyone. When people say hello to her, she speaks very softly and doesn't look at the person. She never asks other people how they are. What do people think of Vone?
a. They think she's shy.
b. They think she's rude and unfriendly.
c. They think she's a hard worker and doesn't have time to talk.

Section two, (language and culture for training and increasing work flexibility) includes

training exercises, the directions to which are explained in the Teacher's Manual. The authors explain that, "Training exercises simulate on-the-job tasks. Each one requires students to follow directions to perform a hands-on task, and at the same time, provides a natural opportunity to practice specific communication strategies" (p. 6). Kinds of tasks contained in the training exercises include filling out a supply request form, completing an assembly task from oral instructions, and following a coded plan to complete an assembly. 
The teacher must follow directions and a script given in the Teacher's Manual in order to use these exercises.

An example of a role-play in section two, occurs in unit seven. The section is entitled, "Understanding Schedule Changes." In role-plays learners practice responding to a request to work extra hours. In this particular example, students practice turning down a request (p.117):

Student A

You're the supervisor. You're behind schedule. You want a worker to stay and work the 5:30 to $9: 30$ shift.

\section{Student B}

You're at work. It's time to go home. You can't stay because you don't have a baby-sitter for your children.

The third sections of the units, (understanding job policies and procedures) usually begin with a reading. The readings typically present factual information, such as benefit information, tax information, and fire prevention. "Using What You've Learned" exercises follow the readings. These often take the form of a checklist asking students to find out, for example, about the benefits their company provides them, or a form of some kind for the students to complete, such as a tax form.

Speaking Up at Work contains many very effective illustrations and in a lesson on clarification, addresses the interpretation of facial expressions. This exercise depicts faces showing confusion and comprehension or agreement. Beneath the illustrations are questions such as, "Any questions?" and "Do you get it?." Students are directed to interpret the facial expressions and respond to the question accordingly (p.9). 
An interesting topic covered in this text is how to respond to rudeness or impatience It is certainly not easy to respond tactfully and assertively to such treatment. This dialogue provides a worthwhile example (p.81):

Mrs. Johnson: I want you to clean the bathrooms and change all the beds on this floor. Nadia: I'm sorry, I don't understand. Could you please explain?

Mrs. Johnson: Listen Nadia, I don't have time to repeat everything for you ten times. I have my own work to do.

Nadia: I know you're busy, Mrs. Johnson, but I don't understand what you want me to do.

Mrs. Johnson: Okay. I want the beds changed and the bathrooms cleaned.

Nadia: Just on this floor, right?

Mrs. Johnson: Right.

Nadia: Thanks, Mrs. Johnson. I know what to do now.

This lesson continues with questions about the dialogue, a list of useful expressions for responding to rudeness, an exercise in which students write down other rude comments they have heard and responses they could make and, finally, three role-plays.

There are other interesting topics included in this text: refusing to work extra hours, beginning and ending conversations, belonging to unions, and knowing what to do when you have forgotten someone's name.

In general, Speaking Up at Work is a good EWP textbook. Although the units are designed to be used sequentially, the organization of the unrelated sections allows for flexibility. It would be possible to skip sections that are not relevant to a particular course. The many clear, well done illustrations would be helpful to learners. Also, learners would find the inclusion of many authentic work-related forms beneficial

Weaknesses of this text have to do with the shallowness in which some topics are explored. The topic of pay is presented with tax information, tax forms, and a description 
of deductions, but pay issues, e.g., methods of payment (hourly wage, piece wage, salary), how to balance earnings and benefits, status, and why some jobs pay better than others, are not introduced. Personal satisfaction, planning, and goals are left out of the section on advancement. Unions are given only a very brief, descriptive mention. Also, the text lacks self-reflection and chances for students to share their own experiences and opinions.

Discrimination, workers' rights, and cross-cultural communication are not addressed at all. It is very unfortunate that these issues are left out. Being able to maintain employment and to advance within the work force means knowing how to cope with discrimination (or perceptions of discrimination), cross-cultural conflict, and understanding one's rights as an employee.

To summarize, this is a good, practical EWP textbook. While the text does aim to teach assertiveness, the topics dealt with and their depth are not likely to raise the eyebrows of company sponsors. Teachers using this text would need to supplement the lessons with class and small group discussions in order to draw out the students' own experiences and help them to reflect on those experiences.

\section{ESL for Action: Problem-Posing at Work}

ESL for Action, by Elsa Roberts Auerbach and Nina Wallerstein is an EWP textbook that applies Paulo Freire's problem-posing approach to teaching workplace English language skills. It is designed for intermediate to advanced ESL students. The authors 
state that this text is about the daily work lives of immigrants; their interactions and concerns (p. v). Thus, the text's emphasis is the lives of immigrant students/workers who work in a variety of occupations. More specifically, the text explores the problems they face, and their need to change or transform their situations. Some of the problems explored in this text include: discrimination, unfair pay, deportation scares, health and safety on the job, and issues related to being a union member.

The authors state that both the teacher's guide and the student book for ESL For Action "....concern education for change, the personal and social changes that we, as teachers, hope to promote in the lives of our students and in our own lives" (p. v). Their goals then are to help students and teachers realize their goals both within and outside the classroom.

The problem-posing approach was created by the Brazilian educator, Paulo Freire. It takes classroom material from students' own lives and asks that they believe in their own knowledge and life experience. Moreover, it asks that they bring the richness of their experiences to the classroom (Auerbach \& Wallerstein, 1987). Auerbach and Wallerstein write in their introduction that, "The first step to promoting action outside the classroom is to transform education inside the classroom" (p. v). To do this, they insist that teachers must create a classroom that is safe--where students can freely express their ideas and opinions, and most importantly, a place where students will generate their own language materials and projects for learning and peer-teaching. Thus, they assert: 
Curriculum is not a product, but a process, which is constantly changing through participant interaction. As students discuss the social contexts of their own life problems, they won't blame themselves for not "making it" in the US and will begin to rely on each other for learning and for promoting change (p. v).

Finally, they hope that, "By changing traditional classroom roles, students will begin to reexamine their traditional workplace roles" (p. v).

ESL For Action is theme-based and includes competencies. Some of the themes explored in each unit are: introductions, getting a job, starting work, making money, getting through the day, acting for health and safety, moving toward equality, and participating in a union. Each of these units is comprised of several topics, one for each lesson.

What makes this text exceptional is not just the educational approach it has adopted, but also the depth and honesty in which it explores its topics. The text is called problemposing rather than problem-solving because it does not offer solutions; it involves students and teachers in the process of moving toward change, toward realizing their dreams. While recognizing that that can be a very long road, Auerbach and Wallerstein hope that their text will make the process a meaningful learning experience.

The lessons in ESL For Action are comprised of three phases: reflection, action, and evaluation. The reflection phase begins with a code or dialogue in which the theme and language points for that lesson are introduced. These are followed by discussion questions and "thinking activities." The discussion questions address the issues in the code. The thinking activities ask learners to articulate their own opinions and experiences, and to draw comparisons between their native cultures and North American culture. For 
example, in the unit entitled "Making Money" the following thinking activity occurs. Here groups of students are asked to identify possible benefits and then to determine whether or not it is a benefit workers have in their native countries (p. 61):

Benefits are extra things that your employer pays in addition to wages. Benefits in each workplace are different. Some jobs have no benefits. In small groups, discuss each benefit and match it with its definition. Do workers in your country get this benefit?

1. paid vacations

2. paid holidays

3. personal days The employer pays if you are not able to work because of illness or accident. The company pays part or all of your medical insurance. The company pays for a certain number of days off that you do not have to explain.

Other benefits included in this list were: sick or disability pay, health insurance, dental insurance, pension/retirement plan, training, life insurance, maternity leave, and education. Next, learners are asked to interview a friend about the benefits he or she receives, and to find out the answers for their own jobs.

In the reflective phase of the lesson there is a reading section where factual information about the theme is presented and stories from other EWP learners are shared. Another example from the "Making Money" unit has a reading section in which wage laws are presented with a short explanation for each. In small groups students are asked to read one of the four laws, discuss it, and present their interpretation to the class. The following is an example of one law and its explanation (p. 56):

1. The law says: You must be paid the wages and salaries you have earned.

This means: Your employer cannot keep your pay if he is short money. Your employer cannot take away an hour's pay if you were five minutes late. Your employer must pay you for all wages, vacation pay, and holiday pay that you earned if you leave a job. 
Readings are followed by the action phase of the lesson. Action activities are competencies which take the form of scenarios and ask groups of students to decide upon the consequences of various actions and role-play them. For example, in the unit entitled "Getting Through The Day" the following competency, or action activity deals with responding to unfair discipline. It begins by asking students if they have ever been disciplined for something they think was not fair. If so, what did they do and what are all the actions they can take if they feel they have been unfairly disciplined. Then this situation is given (p. 76):

Read this dialogue. What do you think Manny should do? On a separate sheet of paper, rank the solutions, first individually and then in groups

Supervisor: This is your fourth mistake today. You can leave for the day.

Manny: I'm sorry. My machine is broken; I reported it.

Supervisor: That's no excuse. You're responsible for your work.

He should: 1. apologize, leave, and do nothing

2. get angry with the boss

3. ask for his union representative

4. quit and look for another job

5. get help from other workers

6. other

A second kind of action called "student action research" asks students to seek additional information from a resource outside of the classroom. For example, in the unit called "Moving Toward Equality" after several lessons on discrimination, students are asked to (p. 127):

Find out the name and phone number of the state commission against discrimination in your state. Find out the number of the EEOC [Equal Employment Opportunity Commission] in your city. Get a copy of the complaint forms and read them in class. Fill them out for one example of discrimination from your experience. 
For the third phase of learning, evaluation, a self- or group- evaluation occurs at the end of each unit. Additionally, grammar and vocabulary exercises appear throughout the lessons.

ESL For Action, unlike other EWP textbooks, addresses and explores some very timely and important workplace issues, sexual harassment, insisting on safety, and pregnancy on the job, to name a few. In the "Moving Toward Equality" unit, sexual harassment is explored. The following thinking activity is presented to help students identify sexual harassment (p. 142):

Comparing Cultures: Here are some complaints about sexual harassment from women workers. In your culture, which behaviors are common and acceptable at work? Which ones make you feel uncomfortable? First answer the questions for your culture and then answer the questions for yourself. Check "?" for behaviors that you aren't sure about or that are sometimes OK (depending on the situation.)

1. A co-worker always whistles at me.

2. The men often make sexual comments about me.

3. The men call us sexual names.

4. A co-worker makes sexual jokes around me.

5. My boss is always touching and pinching me.

6. My boss keeps asking me out.

7. A co-worker keeps asking for sexual favors.

8. My boss said I'll get a raise if I sleep with him.

Students are then asked to explain when and why a behavior is OK if they checked "?" for any of them. Finally, students are asked to rank the kinds of harassment from least to most serious and discuss their answers.

In the "Acting for Health and Safety" unit, competencies are presented that deal not only with insisting on safety, but also on what a worker can do if his/her boss does not remedy a safety problem. Questions are offered to help employees decide what to do: 
How serious is the problem? What will happen if you do nothing? Should you take action by yourself or with others, and what will happen if you do? (p. 104-105). This unit on health and safety continues with readings about filing a complaint with the Occupational Safety and Health Administration (OSHA), group action for health and safety, and refusing unsafe work. It also includes a great deal of information about pregnancy on the job, including attitudes about pregnancy at work and pregnancy rights.

Overall, I believe ESL For Action is an excellent EWP text. The topics it addresses and the depth to which they are explored make this an extremely powerful textbook. It incorporates a good balance of reading, writing, speaking, and listening activities for intermediate to advanced learners. Also, it has a wide variety of kinds of activities. The text works hard to draw out students' opinions and experiences in facing the problems of their lives and striving toward solutions.

There are a few potential problem areas for ESL For Action, but none so serious as to greatly detract from this fine text. First, because the problem-posing approach involves exploring issues that may be controversial, requires students to freely express their opinions, and requires that the teacher mediate class discussions, training for the teacher in problem-posing technique would seem necessary. Secondly, because of the controversial nature of some of the topics presented in this text, it may be difficult to convince an employer that it is the best textbook for use in an on-site EWP course. Finally, as Auerbach and Wallerstein acknowledge in their preface, a published textbook is 
antithetical to the problem-posing approach since in problem-posing, the lesson topics should be generated by the students themselves.

In conclusion, this EWP textbook stands alone in its commitment to empowering students and addressing serious issues related to work and being a worker in the United States. No other text I came across presented such important topics as discrimination, sexual harassment, refusing unsafe work to name a few. Because it integrates language skills successfully, and explores such a variety of topics, it could certainly be used as the sole textbook in an EWP course.

\section{May I Help You? Learning How to Interact with the Public}

May I Help You? by Heidi Spruck Wrigley focuses entirely on interactions by service employees with their customers; thus other aspects of employment are not addressed such as interactions with co-workers and bosses, or workplace conditions. However, the text does emphasize moving up on the job. This text is designed for intermediate level EWP students. Since it covers a number of occupations within the service industry, it could be used by many groups of students and would be appropriate both to already employed service workers or those who wish employment in that industry.

This textbook focuses on the listening and speaking skills needed for success in service industry jobs. It includes a listening component on an additional audio tape. This tape is necessary for use in many of the exercises in this textbook. Because I did not have access 
to the audio tape, this evaluation is somewhat limited. Many of the listening and speaking items presented in this text are, in fact, cultural information about the United States, such as dealing with customer complaints and apologizing for a mistake.

The author's goal, judging by the table of contents, is to train learners to be able to clarify requests, give directions, and demonstrate concern for the customer's needs. Moreover, her emphasis on promotion and continued job searching strategies suggest that it is also her goal that students/employees not get locked into the lowest sector jobs the United States has to offer because they lack the self confidence or know-how to move up.

May I Help You has six chapters, each emphasizing a different function or task: understanding what the customer wants, responding to simple requests for information, dealing with mistakes, dealing with complaints, dealing with special requests, and moving up the career ladder. A variety of public-contact workplaces are represented in this text, such as hotels, fast-food outlets, restaurants, stores, gas stations, and repair shops. The language and situations presented for the occupations within these workplaces are jobspecific, but more often than not, the functions are transferable to other jobs. Some of the skills covered in this textbook are: calculation skills, reading and scanning, writing and spelling, and observation skills.

Each chapter follows this format:

- Overview: introduction

- Listening and Interpreting: students listen to and discuss an interaction on the audio tape

- Role-plays and Peer Evaluations

- Match ups: parts of conversations with two speakers 
- Learning the Language: language functions taught and practiced

- Making it Work: tips for moving up, case studies, discussions

- Getting on to Basics: numerical practice

- Out in the Real World: reflection on one's own experiences, observation exercises

Some aspects of May 1 Help You stand out as being distinctive. They are: peer evaluations, case studies, observation exercises, and the emphasis on moving up. First, each chapter includes a peer evaluation form for a role-play by other students. This is called a "progress report." After students have watched others in their group do a role play, they fill out a report evaluating them. The directions read as follows (p. 50):

To be effective, service employees need to remember many things. They should be friendly and helpful. They need to make sure that they understand what the customer wants; and if appropriate, they should offer the customer additional items. How well did your group do in "playing" the service person? Fill out a progress report for the people you observed.

Four questions are given with three responses: did well, some problems, and needs more practice. The four questions are:

1. Used a friendly tone; looked customer in the eye; appeared helpful; smiled.

2. Asked questions to find out what customer wants; offered choices; gave explanations

3. Was easy to understand; spoke loudly and clearly.

4. Offered customer additional item; explained sales items.

Finally, students rate each other as being "fantastic, pretty good under the circumstances, or not bad"' (p. 50)

Second, like many business textbooks, case studies presenting a situation with several possible responses are included in May I Help You. In this case study, for example, students are directed to discuss the case and decide what Pat should do (p. 51): 
Pat is a waiter in a small restaurant. One day a customer orders salad. Pat says: "What kind of dressing would you like?" The customer answers: "Ranch style, please." The restaurant has only French, Thousand Island, and oil and vinegar dressing. What should Pat do?

1. Pat should say: "What IS Ranch Style? I've never even heard of it."

2. Pat should say: "I'm sorry. We only have French, Thousand Island, and oil and vinegar."

3. Pat should just bring the customer Thousand Island dressing; most customers like it.

4. Pat should say: "I'm sorry. We don't have Ranch Style dressing."

5. Other:

Third, each chapter also contains some observation exercises to be done outside of class by students as they observe real service interaction. For example, this exercise occurs in the chapter on dealing with mistakes on page 80 :

Next time you go to a store, restaurant, or a gas station, pay attention to see if mistakes occur. Pay special attention to the way the employee handled the mistake and then discuss the information with the rest of the class.

Finally, the emphasis put on moving up is unique to the books evaluated for this project. Not only does a whole chapter address the topic, but all of the other chapters contain tips and advice on moving up. For example, in the chapter called, "Responding to Simple Requests for Information" this advice is given (p. 49):

Good clerks do more than just answer questions, they try to be good salespeople, too. Experienced salespeople try to make suggestions and explain special sales. For example, an experienced salesperson might say the following:

At a Clothing Store:

- Can I help you choose a tie to go with that shirt?

- How about a skirt to go with that blouse?

- We have some scarves on sale that would look great with that dress. 
Two other workplaces, a gas station/car wash and a hotel, are also included in this exercise. Students are asked to choose one situation and role-play it acting like an experienced salesperson.

In a "Learning the Language" section on double-checking orders, Wrigley presents several useful ways to confirm an order and includes in the dialogues the fact that sometimes customers mumble. Acknowledging this shows students that it is not always their own fault if they have not understood a request. In this lesson, students are taught to ask "What kind...." and "How many..." in order to clarify a customer's request. For example, (p.12):

Customer: I'd like three chocolate donuts and five (mumble mumble) bars.

Clerk: That's three chocolate donuts, and what kind of bars?

Customer: Glazed buttermilk bars.

Clerk: Here you are, five glazed buttermilk bars.

In a lesson called "Apologizing for a Mistake" the textbook explains that, "Making a mistake can be embarrassing, but experienced employees know what to say when mistakes happen...When service people make a mistake, they usually apologize” (p.65). For example:

Customer: I told you to give me five dollars worth of gas, but the meter didn't stop. Clerk: I'm sorry, that was my mistake. I thought you wanted 10 dollars worth. While it is certainly useful to practice different ways to apologize, often what customers want in situations like these is to know what will be done about it; will he/she (the customer) have to pay for the extra gas? Because Wrigley concentrates solely on workercustomer interaction, she offers no advice about how employees should find out what they 
can do for the customer (in addition to apologizing). Of course, this varies from company to company, so it is an important issue to be able to discuss with one's supervisor.

A similar issue arises in a lesson dealing with customer complaints. This encounter takes place at a lunch counter (p. 88):

Customer: This fish sandwich smells funny.

Clerk: I'm terribly sorry. Would you like to order something else?

This would have been a good opportunity for the textbook to guide students with the language necessary to ask their bosses whether or not it is the policy of the restaurant to allow customers to re-order something, and how that should be done.

In a lesson entitled "Responding to Customer's Requests" the text offers students some ways to say "no" to a request as well as "yes." This is a valuable lesson, because being able to say no politely is very important. Here are some examples (p.111):

Customer: Could I please have cottage cheese instead of French fries with my hamburger?

Waiter: I'm really sorry. We can't make substitutions. But you can order a side order of cottage cheese if you like.

Hotel Guest: Could you come in and chat with me for awhile? I miss my family and need someone to talk to.

Maid: I'm sorry, sir. But we are not allowed to be in the room with guests.

Overall, May I Help You? is a good EWP textbook. One of its main strengths is the peer-evaluations and observation exercises. The variety of exercises, occupations represented, and attractive, clear lay-out make it an interesting and stimulating textbook for intermediate to advanced students. 
Some problems do exist in this text. First, it may be a mistake to focus solely on public-employee interaction and hope for real-world competency. While the customer is of great importance in service occupations, workers and their customers do not interact within a vacuum. How well employees get along with their bosses and co-workers surely has an enormous impact on their relations with others. Additionally, students can learn a great deal about North American culture and English through their communications with others at work. Therefore, I believe it is necessary to include other workplace interactions in an effective service industry EWP textbook.

Secondly, and related to this issue, the exclusion of union information, workers' rights, cross-cultural communication, or encouragement for workers to participate in their workplaces is a mistake. How employees are treated, or perceive they are being treated by their supervisors and co-workers is certainly of great importance to workers' lives Service industry jobs are growing in number, more and more people are employed in service occupations and while interacting successfully with customers is of great importance, how can workers do this if they do not understand their rights, enjoy smooth interactions with co-workers, or feel welcome to participate in their workplace or union?

In conclusion, these shortcomings could be overcome by supplementing the course with additional information and activities aimed at social relations and conflicts at work, assertiveness, and workers' rights. For many things, such as, dealing with customer complaints, and employee benefits, the EWP teacher or planner would have to create some company-specific materials anyway. 
The Working Culture: Book One Cross-Cultural Communication For New Americans

The Working Culture: Book One by David Hemphill, Barbara Pfaffenberger, and Barbara Hockman is a low intermediate text that focuses on cross-cultural communication at work. This is the first book in a two-part series (Book Two is also reviewed in this study)

The authors describe their texts as being sets "...of activities for guiding newcomers in their job and career plans and for enhancing the cross-cultural understanding that is needed for these plans" (p. vii). Furthermore, they stress that these texts are not designed as language teaching texts, although English language skills can be developed through their use. The aim of these texts, they write:

...is to spark awareness and open up discussions of important vocational and interpersonal issues as they are found in the United States in comparison with other countries... The lessons succeed when critical thinking has begun, not when issues have been neatly resolved (p. vii).

The Working Culture: Book One consists of eleven chapters in two parts. Part One, entitled "Cultural Adjustment" includes chapters addressing the themes of the central place of work in American life, living and working in a multicultural country, and work as one's own choice. Part Two, entitled "At Work" includes chapters that address these themes: what employers want from workers, social relations on the job, problems in the workplace, and communication at work. Each chapter begins with a short list of competencies. For instance, chapter one, "Taking a Look at Cultures" lists these competencies (p. 1): 
In this chapter you will:

- learn about the word culture and what it means.

- think about both your own culture and the culture of the United States and compare them.

- think about ways of keeping your own customs in the United States.

- learn about some American customs.

What is exceptional about this textbook is the cross-cultural focus. There are many opportunities to explore and compare cultures through observation, reflection, and discussion. Simon, Dippo, and Schenke (1991) in a discussion of critical reflection and employment education stress the importance of recognizing that changes in ourselves occur when the circumstances we are in change (p. 149). Although they were not writing with non-native speakers in mind, this notion is a crucial part of intercultural success as well. Furthermore, they write:

It is important that the teacher focus class discussion on how changing circumstances lead to changes in ourselves and what brings about a change in circumstances. This is the key to beginning a discussion of what forms of individual and collective action people can take if they are dissatisfied with their everyday working lives (p. 149).

Additionally, the "activity bank" format of the book is unique. Because it was not designed as a sequentially developed course, teachers need not follow the text lesson by lesson. They can skip around choosing lessons that deal with topics that are particularly relevant to their learners and omit others. This flexibility would be very helpful especially in open-entry classes.

The Working Culture: Book One covers some important cultural information, including nonverbal aspects of culture. Chapter Four, "Standards of Politeness and 
Appearance," tackles gestures, some of which (numbers 3, 5,6) are not usually addressed in such discussions (p.32):

In your home country, what gesture do you use to:

1. call the waiter.

2. say "come here"

3. ask someone to wait and not interrupt until you are off the phone.

4. show agreement with something your supervisor is saying.

5 . show disagreement with something your supervisor is saying.

6 . show that you can't hear the speaker very well.

7. show that you don't know or understand something.

Make a gesture for one or two of these ideas. Does the gesture have the same meaning for your classmates? Do you think the American gesture is the same as the gesture in your country?

This is followed by eleven illustrations of common gestures and students are asked to state whether or not these gestures are used in their home countries and if so, what they mean.

Another important topic this text deals with is stereotyping. This is addressed in Chapter Three, "Together and Separate: Living and Working in a Multicultural Country." The activity begins with an explanation of stereotype: "When we have an idea about a whole group of people, then we have stereotyped ideas" (p. 26). Then, students are asked to think of both positive and negative examples of stereotypes they know for Americans.

Finally, students come up with stereotypes they believe Americans have for them.

The text also devotes an entire chapter to time. Chapter Five is called, "Implications of Time." Some of the exercises involve cross-cultural comparison. For example, "Am I On Time?" which presents situations and asks students to give the correct time for such an 
event in their home county and to choose the time they feel would be correct in the United States (p.52):

1. A family invites you to dinner. They say, "Come at 7:00 p.m." You want to be polite. What time should you arrive?

In your country:

In the US: $\begin{array}{llll}\text { a. } 6: 30 & \text { b. } 7: 00 & \text { c. } 7: 10 & \text { d. } 8: 00\end{array}$

2. You have a job interview. It is at 3:00 p.m. What time should you arrive? In your country:
In the US:
a. $2: 00$
b. $2: 45$
c. $3: 00$
d. $3: 10$

This list continues with other situations such as what time one should arrive to meet a friend in a restaurant for lunch at 12:30, to a doctor's appointment at 10:00 a.m., to work at 8:00 a.m., and how much notice an employee should give his/her boss before quitting a job.

A topic unique to The Working Culture Book One and one addressed in an entire chapter is that of emotions. Chapter Ten, entitled "Expressing Emotions on the Job" explores this important topic. One exercise, called "What Can I Do About It?" is particularly noteworthy. Students read case studies and evaluate several possible endings. For example (p. 106):

Carmen is angry because she can't go home yet. She has to wait for Rosa to replace her and Rosa is late. Rosa is often late, and Carmen works overtime for no pay. What will happen if Carmen does each of the following things?

A. Carmen yells at Rosa.

Rosa thinks:

B. Carmen leaves before Rosa arrives.

The boss thinks:

Rosa thinks:

C. Carmen yells at the supervisor. She says, "I'm tired of waiting for Rosa! Can't you make her get here on time?!"

The supervisor thinks: 
D. Carmen talks to the supervisor about the problem. She says, "I don't want this to happen again, and I want to be paid for the extra time that I worked." The supervisor thinks:

E. When Carmen has to replace Rosa, she will be late.

Rosa thinks:

The supervisor thinks:

F. Carmen does nothing.

Rosa thinks:

The supervisor thinks:

Carmen feels:

What do you think Carmen should do?

Chapter Nine addresses problems in the workplace. These problems include social and communication difficulties such as, feelings about a co-worker getting a raise, sexual harassment, feeling overworked, deciding to quit a job, and difficulty getting along with a co-worker. Lesson three of this chapter presents a series of role plays that depict problems between bosses and workers and that encourage students to see things from a boss's point of view. For example, (p. 96):

Sometimes you are happy at work. You think everything is fine and there are no problems. But maybe your boss thinks there is a problem with you. In this activity you will have the chance to think the way the boss thinks.

Role-play 1: The Silent Worker,

The Boss (Stan)

Job: You are the supervisor of the shop in a factory

Situation: You have a new worker named Liu. Liu works hard, but he doesn't speak English. Liu listens when you explain things, but he doesn't ask questions, and he doesn't say anything. You are not sure if Liu understands. You want to know if he understands. What is your problem? Now go talk to Liu about this situation.

The Employee (Liu)

Job: You are a factory worker.

Situation: You work hard. You like your boss, Stan. When your boss explains something, you always understand. So, you don't say anything. But your boss is unhappy. You want to know why your boss is unhappy. What is your problem? Why do you think your boss is unhappy? Now your boss, Stan, is going to talk to you about this problem. 
Overall, The Working Culture Book One is an excellent text for intercultural learning at this English proficiency level. The activity bank concept should be very useful to teachers, although the lessons would need to be supplemented with language lessons and exercises. This is an effective book for getting people talking. Many exercises, like the one exemplified earlier concerning time, "Am I On Time?" are relatively safe kinds of opening up to ask of students. Others certainly require more risk and a teacher using this text would need to be able to create a relaxed, respectful climate in his/her classroom. The exercises are laid out well on the page with lots of space surrounding the text so as not to look like an overwhelming reading task.

Some rather minor problems do exist with this text. It does not cover unions, employee rights, or pay; however, these are addressed in Book Two. Secondly, for some teachers and program planners the need to supplement this text with language materials may be daunting.

Finally, because the text is not designed as a language text, and a language text may need to accompany it, some employers and program sponsors may hesitate to invest in this text for their students. They may press teachers and planners to find a book that teaches both language and intercultural communication; teachers may have a difficult time convincing employers and program planners that this would indeed be the best choice for a textbook. 
In conclusion, The Working Culture: Book One is an outstanding workplace textbook. It is a marvelous resource for teachers with activities that are stimulating, thought provoking and discussion oriented .

The Working Culture: Book Two Career Development for New Americans

The Working Culture: Book Two by David Hemphill, Barbara Pfaffenberger, and Barbara Hockman is a low-intermediate textbook that focuses on moving up and job hunting. Like its counterpart, The Working Culture Book One, this text was not written specifically as an ESL textbook, but recognizes that ESL skills may be developed through its use.

The authors' objectives have already been discussed in the review of Book One, and the objectives are the same for Book Two. Essentially, these texts seek to develop critical thinking and "... to spark awareness and open up discussion of important vocational and interpersonal issues as they are found in the United States in comparison with other countries" (p. vii).

The Working Culture Book Two, like Book One, uses a great deal of cross-cultural comparison, contains very practical information for students, and is a "bank" or store of many activities. These activities include case studies, role-play, brainstorming, openended stories, and problem-solving strategies. Its lessons are theme- and competencybased and not designed as a sequentially developed course. This text has three parts and 
twelve chapters. Part One is entitled "Making Decisions About Work," Part Two is called "Finding a Job and Moving Up," and Part Three, "Economic and Legal Awareness." The text also has a useful appendix. This appendix describes and illustrates 22 entry-level jobs available in the United States. The descriptions include job duties, skills needed to get the job, skills that can sometimes be learned on the job, English needed, places to find such jobs, and salary range.

Some of the topics addressed in Part One are: what is important in a job, training and licensing requirements of certain jobs, English communication needed, and factors in choosing a job. Some of the topics in Part Two include industrial and occupational trends, job search strategies, why some people get hired and others don't, job change, and mobility. Part Three addresses workers' hours, pay, deductions, benefits, and laws that protect workers.

What is exceptional about The Working Culture Book Two is its emphasis on selfreflection. It encourages learners to look at and evaluate their own employment situation. For non-native speakers of English, understanding their employment situation requires a great deal of cultural and language knowledge and this text, through discussion, case studies, and presentation of information does a fine job of helping students to be able to reflect upon their own lives not only to plan their futures, but also to understand themselves better. Simon, Dippo, and Schenke (1991) write that self-assessment must enable both guidance (planning) and social analysis. They state that social analysis occurs through "...activities that promote practice in understanding how one's own thoughts and 
feelings are related to and influenced by the nature of the situations one has been, and is currently, a part of " (p. 151). The self-assessment exercises in The Working Culture: Book Two strike a balance between guidance and social analysis.

Additionally, some of the topics chosen for this text are unique to it. For instance, it is the only text I have found that touches upon how unemployment feels, how to determine acceptable working conditions, or why someone may not have been hired for a job.

The text begins with an examination of what is important in a job, including job status. It explains (p.5):

Job status is the respect other people have for your job. A job has high status if people think it is a good job and would like to be like people who have that job. A job has low status if people think it is not a very good job.

In some countries, teachers have high status. This means that people respect them and want to be like them. In your country do teachers have high status? Do you think teachers in the United States have high status?

How important is status to you when you choose a job?

very important important somewhat important not very important

Status and Salary

What do you think is a high salary? \$

What do you think is a medium salary? \$

What do you think is a low salary? $\$$

Look at this list of jobs:

$\begin{array}{llll}\text { sales clerk } & \text { accountant } & \text { secretary } & \text { bus driver } \\ \text { doctor } & \text { assembler } & \text { taxi driver } & \text { dish washer } \\ \text { farm worker } & \text { baker } & \text { janitor } & \text { bank teller } \\ \text { waiter } & \text { auto mechanic } & \text { hotel housekeeper } & \\ \text { sewing machine operator } & \text { auto mechanic } & \end{array}$

Which ones do you think have high salaries? medium salaries? low salaries? 
In the same chapter, much time is spent helping students to determine what their work priorities are in order to help them choose suitable jobs. Several exercises address something no other texts have and that is the physical working conditions of a job and other environmental factors, such as heat/air conditioning, noise, windows, amount of work, transportation, rules, co-workers, size of work place, and health benefits. It offers students a "Working Conditions Rating Form" that asks students to read a list of factors and rate them on a scale of one to five. Besides working conditions, students also rate the importance of opportunities and personal satisfaction factors (such as opportunities for advancement, chances to use one's talents, enjoyment of the work). They also rate the importance of benefits. Finally, students evaluate their ratings (p.14):

Which five are most important to you? Write them down here.

Tell the class about the kind of job you would like to have. Use some of the ideas in the lists above. Use sentences like the following:

I want a job that has...

I want a job where I can...

It doesn't matter if...

Chapter Three contains important information about training and licensing requirements for some jobs. This can be a source of confusion for many new Americans. After providing lots of information, the lesson concludes with a cross-cultural comparison of ways that people learn their jobs (p. 37):

Way to Learn a Job

School (Degree)

School (Vocational)
Who Learns a Job This Way?

In the US

[ ] a lot of people

[ ] some people

[ ] almost nobody

[ ] a lot of people

[ ] some people

[ ] almost nobody
In My Country ] a lot of people ] some people [ ] almost nobody [ ] a lot of people [ ] some people [ ] almost nobody 
The list continues with other ways to learn a job, such as apprenticing, on-the-job training, learning from a family member or friend, or self-teaching.

Part Two of the text addresses finding a job and moving up. It is in this chapter that unemployment is touched upon (p. 90):

\section{Unemployment Hurts!}

Everybody has problems. People who don't have jobs have problems. Most of them want to find a job as soon as possible. Here are some problems. Which ones are your problems too?

1. I don't have a job, so I don't have much money. But I have a family to support. [ ] This is me. [ ] This isn't me.

2. It's hard work to look for a job. Maybe I don't have enough energy. [ ] This is me. [ ] This isn't me.

3. Sometimes I apply for a job but I don't get it. Then I feel very bad (depressed.) I can't talk to my family. I don't want to look for a job anymore. I don't want to try again. I am discouraged.

[ ] This is me. [ ] This isn't me.

4. I try as hard as I can, and do everything I learned in class, but I still can't find a job. [ ] This is me. [ ] This isn't me.

This lesson continues by presenting some of the special problems people from other countries can have--newness of the application process, English, competition. The exercise asks students to discuss these problems with each other and the teacher, to list other problems they have faced, and to come up with things to do about these problems.

Part Three of The Working Culture Book Two concerns economic and legal awareness. In a section about pay and work hours, case studies follow a presentation of legal information. The case studies ask students to identify the law that is being broken in each instance and whether or not such a law exists in their native countries (p. 146):

1. Sandra is an office worker in a small office. Her boss asks her to answer the phone at lunch time.

2. Antonio is laid off from his job. His supervisor says, "Come back in two weeks to get your check. 
3. Tien makes $\$ 5.00$ an hour. She works 42 hours in one week. She gets paid $\$ 5.00$ an hour for all the hours she worked.

42 hrs. $\times \$ 5.00=\$ 210$

4. Carmen makes $\$ 3.00$ an hour for housework.

5. Ryoko's boss asks her to work 6 hours with no break.

6. Samuel is a waiter. He works 6 days a week. He works 6 hours a day, and he makes $\$ 4.35$ an hour.

7. One week Samuel worked 7 days because another waiter was sick one day. He was paid $\$ 4.35$ an hour for all the hours he worked.

8. Mai is a cashier. One day, she had an accident and broke the cash register. It cost $\$ 35.00$ to fix the cash register. Mai's employer took $\$ 35.00$ from her paycheck to pay for the repair.

9. Linh is a jewelry factory worker. She earns $\$ 8.00$ an hour. Her boss wants her to buy her own jeweler's tools.

Lessons on unions and discrimination follow this same format; information is presented and case studies with cultural comparisons follow.

Overall The Working Culture Book Two is an excellent EWP textbook, particularly when used in conjunction with Book One. The two together cover many important topics, and do a great deal to facilitate intercultural communication. I believe the emphasis on planning for the future and future progression through the job market is extremely important for new Americans. For some, job changing and ways to move up may be very unfamiliar; without texts that address these, many could never move up and would unwittingly be putting themselves in vulnerable positions. Additionally, the appendix of entry-level jobs is an important resource.

Some of the possible problems mentioned in connection with Book One could also be problems for Book Two, namely, that because it is not primarily a language textbook, it may be difficult to convince companies to invest in it. Secondly, the teacher must supplement language materials. Finally, this text contains very few role-plays. Its 
emphasis is on self-evaluation; thus if teachers are not successful with, or comfortable with the discussion format, this textbook selection would not offer effective speaking and listening practice.

To conclude, like Book One, The Working Culture: Book Two is an extraordinary workplace textbook. Students using this text should gain insight into their own working lives as well as acquire intercultural communication skills and learn about job advancement in the United States. Most importantly, the two texts do more than gear students to fit into the job market, they also seek to strengthen students' abilities to consider how they can act to alter the work-related opportunities open to them.

\section{Business World: A Collection of Readings on Contemporary Issues}

Business World by Roger Speagle and William B. Giesecke is a high-intermediate to advanced textbook focusing on current business issues in the United States.

The authors state that their objectives are to improve the English communication skills of those who have a special interest in business. Furthermore, they write, "The text has as its purpose improvement not only of business reading comprehension and vocabulary, but of oral and listening performance as well' (p. iii).

The text is comprised of fifteen chapters in six sections. Each chapter begins with an article concerning an issue relevant to contemporary North American business. The readings are authentic articles from business magazines and journals. The only alterations 
made to the articles have been in shortening them. Vocabulary and sentence structure have not been simplified. The six sections address the following topics: environmental issues, social issues, retailing, economics, energy, and management. Topics of the articles include, making pollution prevention pay, age bias, the free market incentive: self-interest or greed, energy conservation as a billion dollar business, the invisible resource of women on boards, and who gets promoted.

Each lesson begins with an article, which glosses new words in the margins, and continues with vocabulary and structure exercises. The lessons also have a "Business Communication" exercise in which students learn about and practice various forms of business communication, such as memoranda, oral presentations, and letters. Next, each lesson offers an "Action" activity. These often require students to role-play, debate, or create a business scenario. Finally, the lessons conclude with a "Reaction" exercise. These are usually discussion questions.

Chapter Seven, "The Free Market Incentive: Self-Interest vs. Greed," discusses the free market system and Adam Smith's concept of self-interest. It contains some interesting cultural information, particularly the notion of self-interest as being unselfish. The article defines self-interest as, “...the natural effort of every individual to better his own condition" (p. 67) and concludes that this is not selfish because "...the simple desire to better one's life could be claimed as the motive underlying all forms of human effort; e.g., in the arts and sciences, as well as in the economic sphere" (p. 67). This is a lengthy and challenging article. In the first paragraph alone, 16 words were glossed. 
Chapter Seven continues with an exercise using some of the new vocabulary and a structural review exercise. The business communication exercise focuses on using graphs. Students read examples of bar graphs, line graphs, and circle graphs. Then they are asked to re-draw the graphs with new information. The action activity for Chapter Seven is an informal class debate. Students work in teams to debate Adam Smith's concept of selfinterest. Finally, in the reaction phase of the chapter, students answer rather difficult discussion questions. The questions require a good sense of US business in order to answer them. For example (p.77):

1. The author's writing is in pure, free-enterprise, entrepreneurial terms. How theoretical is his defense of free enterprise? That is, are his statements always true when we think of the realities of doing business?

Chapter Three, "Wounded Executives Fight Back on Age Bias," deals with age discrimination. This was the only text found that addressed this topic, and it is the only form of discrimination discussed in Business World. This article presents information about current trends by companies to fire or force early retirement on older executives. This is justified by those doing it because it saves money in salary and pension liabilities and because it allows room at the top for new, younger executives. The article cites examples of real age-bias law suits and presents legal information. It also gives some advice for self-protection, such as awareness of laws and the signs of age bias, keeping notes and copies of commendations, and doing a good job. This is good advice, but neither the article nor the rest of the lesson delineate the signs of age bias, or explore the problem. 
The business communication section for chapter three addresses note taking and summarizing. Students summarize given selections from the article. The action activity is quite interesting; it describes an "exit interview" (one given when an employee leaves a company to help managers understand why workers leave). This activity focuses on types of questions and includes these question types in role-plays. It begins with a presentation of each type of question and gives examples of each. This would certainly be useful information for language students. For example (p. 34):

Open questions: questions that allow the interviewee the most freedom in answering such as, "How would you describe yourself?"

Closed questions: questions which limit the answer such as, "Will you relocate? Does relocation bother you?"

Non-neutral questions: questions that may put pressure on the interviewee to answer in a certain way. For example, "How do you feel about this company's foolish sick leave policy?"

Neutral questions: do not pressure the interviewee to answer in a certain way. As in, "In what kind of work environment are you most comfortable?"

Mirror questions: use the exact words an interviewee used in responding to a question. Such as, A: "I like my present job, but I don't get along with my boss." B: "You don't get along with your boss?"

Searching questions: seeks more information about the interviewee's response. For example, A: "In my last job, I learned how to supervise the work of others." B: "How many people did you supervise?"

A strength of Business World is that it uses authentic magazine and journal articles. Sources for the articles include: Harvard Business Review, Business Week, and Fortune. Surely students would find exposure to such magazines very helpful and confidence- 
boosting. However, this makes it a very challenging text, in my opinion. Perhaps, highadvanced would be a better proficiency level indication than high-intermediate to advanced.

For students and teachers who are not only interested in business, but also quite knowledgeable about it, Business World could be a well-matched textbook selection. The glossing of words and answer key allow some self-study, but most of the activities require groups. The text contains a good variety of activities, debates, panel discussions, and interviews. It also exposes students to many forms of business communication, abstracts, resumes, memoranda, and others

There are several problems with this text. First, no mention is made of unions. It is important for people who are, or intend to become managers to understand unions even if as managers, they will not be union members; their employees may be union members Also, no intercultural communication or problems are addressed. Given the culturally diverse make-up of the United States' work force, this is a crucial part of being a business manager today and a good business English text ought to address it. Moran and Harris (1987) write that a manager's, “...success or failure working in multicultural environments depends upon awareness and understanding of fundamental differences in culture" (p. 74)

Secondly, while the age-bias article was important and the only one of its kind found in the textbooks selected for this study, more workers' rights information, as well as other kinds of discrimination should have been included. Likewise, a deeper analysis of the underlying causes of such problems, and greater discussion of the kinds of resources and 
actions available to employees would have added greatly to the effectiveness of this text. Third, although the text aims to improve spoken communication as well as reading, no conversation models are offered.

In conclusion, Business World is an adequate and very advanced reading text. While its reading selections are interesting and cover a broad range of business issues, its failure to address such timely topics as discrimination and intercultural communication is a disappointment. It contains a good variety of activities, including many that require advanced speaking skills and many written exercises that allow for self-study.

\section{Working World: Language and Culture of the Job Market}

Working World by Maria Maniscalco Baskin and Lois Wasserman Morton is a reading text emphasizing workplace language and culture. A proficiency level is not stated, but I would suggest it be used with intermediate to advanced students.

The authors write in their preface that this textbook teaches the language and presents the information necessary for getting, keeping, and advancing in a job. They point out that this information is not generally available to ESL students. The authors write, "We focus on the ongoing adjustment to American employment practices and on the cultural misperceptions that many non-native job seekers experience" (p. vii). Furthermore, the authors emphasize that often cultural differences go unrecognized as such and this may lead to conflicts. 
The text consists of fifteen chapters each focused on a reading passage. The readings are stories, or case studies, told from the point of view of ESL students/workers. These stories were created based on information gathered from counselors, social workers, immigrants, and experts in cross cultural communication. Topics of these readings include time, research and planning for employment, interview behavior--both verbal and nonverbal, upward mobility, rights, and fringe benefits

The authors provide a description of each chapter in their preface. Each chapter is organized as follows (pp. vii-viii):

1. A situational passage illustrating a cultural misperception serves to stimulate thought and discussion. This reading is followed by comprehension and inference questions, vocabulary exercises, grammar review, and idioms.

2. An informational passage containing practical cultural information about the working world helps the reader understand the cultural misperception illustrated in the situational passage. This second passage also contains tips or guidelines to follow in unfamiliar situations. The reading is followed by comprehension questions, discussion, and creative applications, in the form of dialogues, group-oriented tasks, and applied practice.

Finally, they write (p. viii):

Most cultural misperceptions occur because of lack of information about cultural practices. This kind of information is not taught in the classroom but is understood by natives as "the way things are done." These unwritten rules are not obvious to the nonnative person, who must learn them through trial and error, often at the cost of confusion, resentment, distress, and embarrassment. It is our hope that this book provides information that will facilitate the non-native's adjustment to the working world.

This EWP text, unlike the others, includes the topic of culture shock. Chapter One begins with a reading describing a group of ESL students' unmet expectations of the United States. The information passage for this issue (pp. 9-10), while brief, does present 
a clear overview of culture shock phases. It is disappointing that only two discussion questions following the passage ask students to relate their own experiences of culture shock. They are (p.12):

1. What do you think of these phases of adjustment, and can you identify with any of them?

2. What advice would you give to someone who was entering the United States to live?

In Chapter Ten, "Interview Behavior: Nonverbal," the reading (pp. 152-153) describes a negative interviewing experience. The non-native speaker in this scenario is confused by what she sees as conflicting messages such as the informal dress of the interviewer; the interviewer's cluttered, disorganized desk; and a late start for the interview. Some good questions follow this reading: "Why did the cluttered desk disturb her?," "Why was she confused about the interview?," and "Why was she worried about where to sit?" (p. 153154) but no analysis is given about kinesics or proxemics. Thus, a teacher using this text would have to be familiar with these concepts. The reading passage presents tips about nonverbal behavior for interviews in the United States, for example, a firm handshake, making eye contact, posture, and dress. However, no cross-cultural comparisons are made. Questions following this passage emphasize why certain nonverbal behaviors need to be adopted (p. 160):

1. Why is a firm handshake important?

2. Why is it important to make eye contact with an interviewer? In a later section, two questions ask students about their native countries (p. 160-161):

1. In your native country, is the use of space different from the use of space in the United States? In your country, how close do people stand when they speak? 
2. How does nonverbal communication differ in your native culture in terms of physical contact, eye contact, dress, gestures, facial expressions, and time?

Chapter Twelve, "On-The-Job Behavior: Interaction," deals with employee performance reviews. This was the only text found that devoted an entire chapter to this important topic. Two case studies are presented in the first reading each depicting a kind of employer dissatisfaction that might be mystifying to employees from other cultures. In both cases, the employees are very hard-working, conscientious workers. In the first instance, an office worker is told that she is not managing her time effectively, and in the second case, an employee is told that he does not take enough initiative or give enough feedback. Both scenarios also convey the non-native speaker's sense of the evaluation.

The informational passage that follows these two cases includes a sample of a very thorough, lengthy work evaluation form. Surely it is helpful for students to see the range of possible factors for an evaluation. Although it is not suggested, this could be used by students for self-evaluation.

In sum, Working World is a fair EWP reading text. It covers some very significant topics such as culture shock, performance reviews, and nonverbal communication, but without allowing learners to explore them in depth. The format of first presenting a personal account of the theme as a case study, and later offering an informational passage gives the theme an interesting balance.

There are some fairly serious weaknesses in Working World. First, themes are merely presented, but not explored; that is, little chance is given for students to relate their experiences and problems, raise their concerns, or begin to develop strategies to address 
the difficulties they face as workers in a new culture. Auerbach and Burgess (1985) write that, "Not exploring the economic or social context of ... problems may reinforce students' sense of helplessness" (p. 480). Factual information and resources about unions, safety, and rights are presented without a chance for reflection, discussion, or critical thinking.

For example, a scenario in the chapter on rights and fringe benefits, addresses the problem of overtime. In this case, too much overtime work is required of an office worker, Lee. When Lee confesses her unhappiness to a co-worker, the co-worker tells Lee that she should discuss it with her boss. The reading continues not with Lee approaching her boss, but with her re-living her job interview at which her boss told Lee there would be some overtime and she remembered agreeing to that. She concludes that they each had different interpretations of how much some overtime meant. While the chapter does offer descriptions and definitions of legal requirements regarding workers' rights, it does not offer advice or models of how to negotiate for changes with the boss, or what to do if no compromise can be reached, nor does it ask students to relate their own experiences.

Secondly, no cross-cultural comparisons are brought out. This seems very strange in a text emphasizing culture. Although each case study depicts a non-native speaker, nothing about his/her native culture is relayed. Thus, cultural adjustment is relayed as being a oneway process. Auerbach and Burgess write in a review of survival English texts, "In practice, the norms of American culture are often presented without reference to students' experience or exploration of cultural differences. Readings and cultural notes suggest 
rules for behavior..." (p. 486). The questions exemplified above for the informational passage in Chapter Ten, "Interview Behavior: Non-verbal," reiterate and reinforce students' need to adopt certain behaviors. What is more, Auerbach and Burgess write that viewing cultural adjustment as one-sided, “...violate[s] a basic principle of adult education by concentrating on what students do not know rather than using prior knowledge and experience as a bridge for learning" (p. 487).

In conclusion, Working World fails to live up to the goals stated in its preface. The authors stated that they focused on "the ongoing adjustment to American employment practices and on the cultural misperceptions that many non-native job seekers experience" (p. vii), but adjustment is regarded as simply being adoption of North American norms. If teachers using this book are able to supplement the topics with class and small group discussions, cultural comparison, and analysis, it could be a useful text in a highintermediate to advanced EWP course.

\section{The Working Experience 1}

The Working Experience 1 by Jeanne H Smith and Harry Ringel is the first in a threepart series of EWP readers. Book One is designed for use in low-beginning level classes, Book Two for high-beginning, and Book Three for low-intermediate. The text emphasizes the working experiences of ESL learners at work in the United States, and in their native countries. 
Each chapter centers around a reading taken from oral and written stories of adult ESL students telling of their own work experiences. The voices of each of the students come through strongly in the readings. The readings are simple, short, and candid.

The text consists of 15 chapters each addressing a different topic. Some of the topics include: women's work, being new on the job, money, the boss, respect, and friends. Each chapter begins with a short reading. This is followed by comprehension questions and vocabulary exercises, such as choosing the correct word or word form to fill-in a blank in a sentence, and matching definitions to new vocabulary. Structure exercises are also included, such as making plural nouns, choosing the correct verb form to fill-in a blank in a sentence, and combining sentences. The chapters also include practice with numbers and calculating. Finally, the chapters have a "Follow-up" section which contains discussion questions about the reading, and gives students the opportunity to relay their own experiences.

This series is distinguished by the fact that each of the three texts develop similar themes making it possible to use them in a multi-level class. This ought to be very useful to teachers and students because it allows for whole class activities and discussions, even though students may actually be reading different texts.

Because the readings in The Working Experience come from students themselves, they depict a much grittier understanding of the way things are than most of the other textbooks have done. For instance, this paragraph entitled "The Boss" (p. 8): 
I won't work in a factory. Bosses in factories don't respect people or treat them equally. They sometimes scream and talk nasty. Bosses get better jobs and more money. Workers do the hard work and make less money.

In the follow-up section for this chapter, students are asked to answer questions as the writer/speaker would, and then to answer them giving their own opinions. The questions include: "Who gets better jobs?," "How do bosses treat workers?," and "Who gets more money?" Finally, students are asked about their own bosses.

Another example can be found in the passage called, "Money" (p. 24):

At my job, the company pays me $\$ 4.25$ per hour. It pays me by check. But the pay at this company never goes up... and the benefits are no good. I get benefits only for prescription medicine and for glasses. I pay $\$ 80$ a month for this health benefit... My salary is too low. I lose too much money to benefits and taxes...

While this is a realistic grievance and well expressed, it is disappointing that the chapter leaves the issue at mere complaint. The follow-up questions do not examine the issues the reading raises.

A final example of a candid passage is entitled, "Respect" (p. 40):

I started working in a restaurant when I was 18 years old. I worked 10 hours a day from Monday through Saturday. That was too many hours and too much hard work for me. Also, the pay wasn't good.

One day the owner of the restaurant started yelling at me. He criticized everything I did. He was very disrespectful. Then he told me he wanted me to work more hours for the same pay. I told him he had to treat me with respect. Otherwise, I wouldn't stay.

This is important because it illustrates a worker standing up for herself, but it is also problematic. It depicts a worker expressing anger rather than negotiating, and offers no advice about how to handle such a situation. 
In the chapter called, "New On The Job," a new worker describes her feelings at work. This passage does a good job of conveying the stress and difficulty of her experience ( $p$. 52):

I work in a belt factory. This is my first job in America. This job is hard because nobody knows me. I can't speak English...In this job I'm like a child. I can't speak. I don't understand what people say to me. I never know if they want me to do something. I'm nervous all day...

It is unfortunate that follow-up questions for this passage fail to elicit students' own experiences. Instead of helping students to focus on and relate their feelings as workers in the United States, the questions ask, "What was your first job in America? How did you learn your job?" This second question especially seems to be a mismatch because the reading passage does not mention learning a job.

Overall, the readings in The Working Experience are interesting and unusually honest. The use of photographs and by-lines of the writers/interviewees adds to the sense that they are real people. The workers' voices come through strongly; it is enlightening to hear their side of working in the United States. Students should find the short readings unintimidating. Teachers, however, would need to increase the number of discussion questions, and create some that elicit students' own experiences.

Weaknesses of The Working Experience text have to do with its lack of exploration of the issues it raises. Because many of the readings express justified grievances, but offer or allow for no action it may be that a textbook like this would only serve to reinforce feelings of powerlessness for the students. Thus, teachers would need to supplement chapters with activities that help students develop strategies to question and change their 
situations, otherwise students may get the message that they are stuck and helpless. Additionally, more discussion questions for each chapter would be helpful, particularly questions like the first example from "Bosses" that asks students to express their own opinions.

To summarize, The Working Experience 1 is a refreshingly honest EWP reading text. The voices, feelings, and ideas of non-native English speaking workers is heard and expressed through simple, and compelling readings. The exercises allow for self-study. The multi-leveled series could be an asset for teachers of multi-level classes.

\section{English Works!}

English Works! by Joan Rubin, Sharon McKay, and Inaam Mansoor is an intermediate level listening text. The authors explain their emphasis on listening by stating, “...most people spend sixty percent of every day listening" (p. iv) and recognizing that few instructional materials focus on listening skills. A video tape used with this text provides context for the listening segments. As students listen to an interaction, they can also watch it. This text would be nearly impossible to use without the video tape. This review was conducted by viewing only the promotional demonstration tape. The demonstration tape was limited to only part of one lesson.

The authors also explain that their text uses a strategy-based approach to learning to listen. They believe that by focusing on the listening process students will become better 
able to listen to authentic language. They write of their approach, "It also empowers learners to be more independent; they know how to listen and are able to continue listening in challenging situations outside of the classroom, especially on the job" (p. iv). In addition to listening, English Works also teaches speaking and reading.

The text, organized functionally, has ten units each addressing a functional topic, such as interviewing for a better job, asking for elaboration of a request or order, dealing with mistakes, making small talk, and working safely. Each lesson contains both a listening (video) and a speaking/reading section. Each video segment depicts a critical interaction between several characters. The listening portion begins with extensive pre-listening activities to get learners thinking about the topic. Students first watch the video without sound. This is followed by discussions, re-viewing the video with sound, more discussion, predictions of what will happen next, and a chance for students to evaluate their listening strategies. Finally, students listen and watch again, this time focusing on picking up details. A contact assignment is typically given as homework. This task asks students to find examples of the topic and/or interaction outside of the classroom.

The speaking/reading sections of each lesson further develop the topic of the video. Students answer comprehension questions, complete vocabulary exercises, and read a summary of the video segment. Conversation practice in which students practice phrases and vocabulary introduced by the topic is also provided. Additionally, each speaking/reading section offers a "cultural exchange." This gives learners an opportunity to share information from their native cultures about the topic. 
It is the listening focus that makes English Works an exceptional EWP textbook. As the authors state, there are not enough instructional materials for teaching listening and it is such a crucial skill to acquire particularly for work. The use of video as an aid for listening is also an interesting addition.

Most of the interactions portrayed in the text depict a communication problem, and one that is usually between a boss and an employee. More often than not, there is a strong sense of the boss's authority and power over the employee. The following dialogue from Unit Four, "Reading Job Postings," illustrates an example of an employee interviewing for a job for which he does not meet the necessary requirements (p. 48):

Mr. Jones: What is your experience in maintenance?

Boju: $\quad$ I do all the maintenance at my house. I have a lot of experience in maintenance.

Mr. Jones: This job requires three years' experience in hospital maintenance.

Boju: I'm sure I can do it.

Mr. Jones: How long have you worked at this hospital?

Boju: $\quad$ Two months

Mr. Jones: (impatiently) You have to be here at least one year to be a supervisor. Didn't you read the requirements for the job?

In another example, from Unit Seven "Asking for Clarification," an employee inappropriately requests a schedule change (p. 114):

Julio: $\quad$ Mr. Walters! I need to talk to you. You have to change my work schedule to the day shift!

Mr. Walters: That's very interesting. I have to change your schedule. And is there a good reason for this--demand?

Julio: Well, I have a new girlfriend! Right now we're on opposite shifts, so there's no time to see her. 
This unit continues with practice in requesting a schedule change. This includes the employee stating his/her needs, giving a good reason for the request, and negotiating the change with the supervisor

The contact assignment for Unit Seven asks students to do three things. First, to think of three good reasons for which they might need to request a schedule change. Second, they are instructed to interview an employer they know, and to ask him/her what was the best reason an employee had given for a schedule change, what was the worst reason, and what was the funniest reason. Third, students interview a friend who has had to change a schedule and ask him/her what was said and whether or not he/she was successful.

The cultural exchanges in each unit provide a chance for cross-cultural comparison. The following example occurs in Unit Five "Small Talk." Students are instructed to discuss the questions (p. 69):

1. Do you have "small talk" in your language?

2. What are three topics you make small talk about in your language?

3. Give an example of how you make small talk with someone in your country. Additionally, Unit Five offers advice on small talk. It states that "when someone makes small talk with you, you should: Answer the speaker (you can agree or disagree). It is important also to give new information or ask a question that keeps the conversation going" (p. 63).

A second example of a cultural exchange activity takes place in Unit Three "Dealing With Mistakes." In this example, a non-native English speaking worker offers advice to another non-native speaker (p. 42): 
Phuong: In our culture, we are sometimes ashamed when we make a mistake. So, we don't say anything.

Aakhu: But here, people want to hear you apologize. It is the custom. I try to do that with everyone: customers, co-workers, and supervisors. One time I didn't, and the customer got really mad.

Overall, English Works is a very good listening text. The video accompaniment for the listening portions certainly increase their effectiveness. The use of five characters to illustrate the interactions adds interest and a story-like continuity to the text.

There are several problems with this text. First, because of the vital link between the video segments and the textual information, use of the text is completely dependent on the video. This does not allow teachers much flexibility in classroom routine.

A second problem is the omission of any discussion of unions, employee rights, or benefits. Not only are these not discussed, they are not even mentioned. The safety unit, a good candidate for some discussion about workers' rights, concentrates solely on the use of warnings.

Third, the consistent depiction of employers as being very authoritative in this text may serve to perpetuate feelings of fear and helplessness for many students, particularly since a one-way channel of power going from the boss to the employee is all that is depicted.

In conclusion, English Works has some appealing strengths, namely its focus on listening and the use of video as a teaching tool. It covers the usual EWP topics, such as asking for clarification, apologizing, and dealing with mistakes, and unlike many texts, includes safety as a topic. However, neglecting to address the important topics of unions 
and workers' rights, means that teachers using this text will have to supplement union and legal rights information. 


\section{CHAPTER V}

\section{DISCUSSION OF THE RESULTS}

This chapter reviews the study and discusses the results of both the descriptive and indepth evaluations. General conclusions drawn from the study are presented and their implications for teaching EWP and ESL are examined. The limitations and methodological problems of this study are also considered.

\section{Overview of the Study}

This study reviewed twenty recent EWP textbooks. All of the textbooks were designed for use in beginning or intermediate level classes, and as generic EWP texts; that is, none of them were job-specific (though some of them did represent an area of employment e.g., service industry, business, or manufacturing). The descriptive evaluations, shown as a matrix, revealed basic information about each text, described some of its contents, and evaluated how well the text dealt with the issues of cultural diversity, intercultural communication, job searching and advancement, workers' rights, and unionism. The in-depth evaluations, written as book reviews, delved more deeply into 
ten of the twenty texts. Detailed descriptions, discussion of weaknesses, and judgments about these were made.

The research questions this study sought to answer were: (1) What textbooks specifically designed for EWP are currently available? (2) How is the workplace culture characterized and represented in the text? (3) What knowledge does the worker/learner gain about working in the United States (specifically regarding unions, rights, career planning and advancement, and intercultural communication), and how does this knowledge benefit him/her?

Additionally, eight criteria for a good EWP textbook were listed in the method section of this study. These served as weights, or considerations for the in-depth evaluations. The criteria are as follows:

- realistic situations depicted and explored

- informal and formal registers modeled

- many kinds of workplace relationships represented

- non-verbal as well as verbal communication modeled

- workplace depicted as being culturally diverse

- work values explored cross-culturally

- intercultural communication facilitated

- learners prepared to be participants in their workplace and/or union

\section{Summary of What was Found}

Most of the texts reviewed here do characterize the North American workplace as a culture by offering information and advice about its norms, rules, and values.

Additionally, the workplace is characterized as being hierarchical, although a good number of textbooks furnish examples of employees asserting themselves to their bosses. Most of 
the texts depict the workplace as being culturally diverse through the use of illustrations, photographs, and names for characters. A small number of texts deal with conflict among workers, but most depict only work-centered interaction that involves a minimum of communication.

Table III delineates some of the topics covered successfully in the texts studied. Only two of the texts in this study do an excellent job of exploring unionism. Two others present information about unions without exploration. Three of the texts cover workers' rights well; six others mention workers' rights or offer brief, factual legal information, but do not allow learners to investigate rights. Eleven texts consider advancement and job hunting adequately, but only four do so very well. Four textbooks explore intercultural communication well and only two employ cultural comparison. Finally, only four texts effectively address non-verbal communication.

\section{TABLE III \\ Topics Covered In Texts}

\begin{tabular}{|c|c|c|c|c|c|}
\hline UNIONS & $\begin{array}{l}\text { WORKERS' } \\
\text { RIGHTS }\end{array}$ & $\begin{array}{l}\text { ADVANCE- } \\
\text { MENT \& } \\
\text { JOB HUNT }\end{array}$ & $\begin{array}{l}\text { INTER- } \\
\text { CULTURAL } \\
\text { COMM }\end{array}$ & $\begin{array}{l}\text { CULTURAL } \\
\text { COMPARISON }\end{array}$ & $\begin{array}{l}\text { NON- } \\
\text { VERBAL } \\
\text { COMM }\end{array}$ \\
\hline & ESL For Action & The Work Cult 2 & ESL For Actic & ESI & Speaking Up \\
\hline Cult 2 & $\begin{array}{l}\text { The Work Cult } 1 \\
\text { The Work Cult } 2\end{array}$ & $\begin{array}{l}\text { May I Help You } \\
\text { Work In Eng } 1 \\
\text { Work In Eng } 2\end{array}$ & $\begin{array}{l}\text { The Work Cult } 1 \\
\text { The Work Cult } 2 \\
\text { Bus Venture } 1\end{array}$ & The Work Cult 1 & $\begin{array}{l}\text { The Work Cult } 1 \\
\text { Working World } \\
\text { English Works }\end{array}$ \\
\hline
\end{tabular}

Table IV lists the language proficiency level of each text. Six texts could be used at the beginning level, nine could be used at the beginning-intermediate level, two could be 
used with intermediate students, and three were designed for use with intermediateadvanced classes.

\begin{tabular}{|c|c|c|c|}
\hline \multirow[b]{2}{*}{ BEGINNING } & \multicolumn{2}{|c|}{$\begin{array}{c}\text { TABLE IV } \\
\text { Proficiency Levels of the Texts }\end{array}$} & \\
\hline & $\begin{array}{l}\text { BEGINNING- } \\
\text { INTERMEDIATE }\end{array}$ & INTERMEDIATE & $\begin{array}{l}\text { INTERMEDIATE } \\
\text { ADVANCED }\end{array}$ \\
\hline $\begin{array}{l}\text { The Working Experience } 1 \\
\text { Your First Job } \\
\text { Working In English } 1 \\
\text { Day By Day } \\
\text { Joblines } \\
\text { Workskills Book } 1\end{array}$ & $\begin{array}{l}\text { Let's Work Safely } \\
\text { Speaking Up At Work } \\
\text { The Working Culture 1, } 2 \\
\text { The Working Experience 2 } \\
\text { English Works } \\
\text { Business Venture 1 } \\
\text { Working In English } 2 \\
\text { Workskills Book 2 }\end{array}$ & $\begin{array}{l}\text { May I Help You } \\
\text { Business Objectives }\end{array}$ & $\begin{array}{l}\text { ESL For Action } \\
\text { Business World } \\
\text { The Working World }\end{array}$ \\
\hline
\end{tabular}

Table $\mathrm{V}$ indicates the focus of each text studied. There is an almost equal number of reading texts and listening/speaking texts. However, only three reading texts are at the beginning level while all of the listening/speaking texts are at the beginning and beginningintermediate levels. Although some texts include writing exercises, none focus on writing. Three texts in this study emphasize the lives of workers, two focus on cross-cultural communication, and one each focuses on advancement, culture, and safety. Three texts teach business English. 
TABLE V

Focus of the Texts

\begin{tabular}{|c|c|c|c|c|c|c|}
\hline READING & $\begin{array}{l}\text { LISTENING/ } \\
\text { SPEAKING }\end{array}$ & $\begin{array}{l}\text { WORKERS } \\
\text { LIVES }\end{array}$ & $\begin{array}{l}\text { WORK- } \\
\text { PLACE } \\
\text { CULTURE }\end{array}$ & $\begin{array}{l}\text { CROSS- } \\
\text { CULTURAL } \\
\text { COMM. }\end{array}$ & $\begin{array}{l}\text { ADVANCE- } \\
\text { MENT }\end{array}$ & SAFETY \\
\hline $\begin{array}{l}\text { Working } \\
\text { World } \\
\text { The Working } \\
\text { Exp } 1 \& 2 \\
\text { Business } \\
\text { World } \\
\text { Joblines }\end{array}$ & $\begin{array}{l}\text { Speaking Up } \\
\text { At Work } \\
\text { May I Help } \\
\text { You? } \\
\text { English } \\
\text { Works! } \\
\text { Working In } \\
\text { English 1. } 2 \\
\text { Day By Day } \\
\text { Workskills } 1\end{array}$ & $\begin{array}{l}\text { ESL For } \\
\text { Action } \\
\text { The Working } \\
\text { Exp } 1 \& 2\end{array}$ & $\begin{array}{l}\text { Working } \\
\text { World }\end{array}$ & $\begin{array}{r}\text { The Working } \\
\text { Culture } 1.2\end{array}$ & $\begin{array}{l}\text { The Working } \\
\text { Culture } 2\end{array}$ & $\begin{array}{l}\text { Let's Work } \\
\text { Safelv }\end{array}$ \\
\hline
\end{tabular}

Table VI shows what type of organization each text follows. Eight of the texts follow a topical/functional syllabus, five are competency-based, three are problem-posing, three are organized thematically, and six topically. As can be seen five of the texts are organized in more than one way.

\section{TABLE VI \\ Organization of the Texts}

\begin{tabular}{|c|c|c|c|c|}
\hline FUNCT/TOPICAL & $\begin{array}{l}\text { COMPETENCY- } \\
\text { BASED }\end{array}$ & $\begin{array}{l}\text { PROBLEM- } \\
\text { POSING }\end{array}$ & THEME-BASED & TOPICAL \\
\hline Speaking Up & Let's Work Safely & ESL For Action & ESL For Action & Let's Work Safely \\
\hline May I Help You? & ESL for Action & The Working Cult 1 & The Working Cult I & Business World \\
\hline English Works & Working World & The Working Cult 2 & The Working Cult 2 & Working World \\
\hline Your First Job & Working In Eng 1 & & & The Work Exp 1,2 \\
\hline Business Venture 1 & Working In Eng 2 & & & Joblines \\
\hline
\end{tabular}




\section{CONCLUSIONS}

The three central concerns of this textbook evaluation are: social implications of textbook contents, portrayal of workplace culture and relationships, and exploration of issues of conflict and unfairness at work. Only three of the ten texts evaluated in-depth manage these concerns superbly. They are ESL For Action, The Working Culture 1, and The Working Culture 2. Of the other seven texts, Speaking Up At Work covers them adequately. The other six textbooks failed to manage all of these concerns in a meaningful, informative way.

A good EWP textbook needs to be grounded in the realizations that discrimination and unfairness exist in American workplaces, that refugees and immigrants are frequently channeled into the lowest sector jobs regardless of their expertise, and that changes in the economy cause jobs to be created, terminated, and transformed very rapidly. Texts built on this foundation can then explore issues of conflict, work relationships, participation, and promotion in a way that is meaningful and realistic. Ultimately, this can empower learners to transform what is unfair or unacceptable in their working lives.

This evaluation concludes that few EWP textbooks explore or even address issues that greatly impact the kinds of lives students will live in the United States; issues such as unions, rights, intercultural communication, and cross-cultural comparison. Most EWP texts also fail to increase workers' flexibility by failing to include job search strategies and literacy skills including writing. Finally many texts fail to realize that by trying to achieve 
neutrality, and thus avoiding the topics of unions, discrimination, and workers' rights, they perpetuate a status quo that maintains learners' powerlessness.

Five generalizations can be made on the basis of these results. First, most of these EWP texts fail to prepare students for the rapidly changing, less stable job market. Such preparation would include learning the skills of job seeking, learning new and transferable skills, coping with problems, advancing, and getting along with others. McGroaty (1993) writes, "The implications for language skills in this context [less stable job market] are manifold: Workers will need the language skills necessary not only to follow instructions and take care of routine, repetitious transactions, but also to solve problems and trouble shoot solutions" (p. 88). The lack of preparation may leave students/workers behind in the lowest paying jobs, or worse, as unemployed workers.

Second, the emphasis on listening/speaking at the beginning levels rather than reading and writing indicates that reading and writing may be considered less important for EWP students; however, literacy skills would contribute to worker flexibility and retraining. Certainly, problems with literacy are major contributors to feelings of powerlessness and frustration. Literacy skills are important workplace skills.

Third, all but a few texts fail to inform about and explore issues of unions, workers' rights, and intercultural communication. Thus, students are not well prepared to be active participants in their workplaces and/or unions. What is excluded from textbooks and curricula is as important to how reality is perceived by students as is what is included (Auerbach \& Burgess, 1985). Without the chance to explore and examine topics so 
influential to their lives, students may be left believing that they are powerless and that the conflicts they encounter are their own fault. However, some of the texts do deal with assertion, especially concerning safety, and also for turning down requests to work, but these are all rather personal, individual assertions. Only one text discusses collective action, and only three encourage problem-posing action by students as they strive for safer, more humane work experiences.

Fourth, the lack of cross-cultural comparison in most of the texts studied leads students to believe that cultural adjustment is a one-way, all-or-nothing process. More activities and discussion are needed about culture learning and choices to be made about the degree to which students are willing to change in order to fit into a new culture. Furthermore, culture lessons that are one-sided conflict with adult learning theory by emphasizing what learners do not know rather than calling upon what they do know (Auerbach \& Burgess 1985).

Fifth, it may be that some textbook writers and publishers have chosen to avoid certain topics in the hopes of maintaining a kind of social or political neutrality. Some topics, namely unions and workers' rights, and some language functions such as refusing, complaining, disagreeing, or criticizing may seem controversial particularly to company managers. However, even by avoiding these issues neutrality is not possible. Shore (1992) explains that all forms of education are political, because they either enable or inhibit students' questioning of society. This in turn either develops critical thought or dependence on authority to be told what to do and what things mean. Furthermore, 
Auerbach and Burgess (1985) argue that no curriculum is neutral because each, explicitly and implicitly, depicts a particular view of social order which in turn shapes students' perceptions of reality and their roles outside the classroom.

There are some positive generalizations to be made about the EWP textbooks reviewed in this study. To begin, all but a few represent the workplace as being culturally diverse and depict people of color and of various ethnicities in supervisory as well as employee positions. This is done through the use of illustrations, photographs, and names.

Secondly, more than half of the texts cover social relations at work as well as workrelated interaction. Developing language skills for social interaction can contribute to workers' job-interviewing success, sense of involvement with others at the work site, and their overall flexibility. Belfiore and Burnaby (1984) report that social language comprises a large part of communication in most jobs. More than half of the texts also include culture sections to introduce students to North American customs, especially those related to working. These too can help learners work, and advance successfully

Finally, with few exceptions, the texts of this study are attractively designed. Exercises, reading passages, and activities are laid-out well and clearly presented. Many texts use photographs, drawings, cartoons, and charts to illustrate the lessons. Additionally, most of the texts contain a wide variety of exercises and activities. These can appeal to and develop different learning strategies among the learners.

Auerbach and Burgess (1985) write, "The choices that educators make reflect their views of the learning process, the social context for learning, and the students' place in 
society. These choices have a very real impact on students" (p. 476). Thus, choosing a textbook carries a great deal of responsibility, but textbooks need not limit a teacher entirely. Teachers often have the freedom to supplement textbooks with other materials that are specifically relevant to the class, explore an important topic more thoroughly or differently, or add content of interest. EWP teachers especially must tailor and supplement materials to fit the realities of a particular work site. For example, they may use actual forms, memos, and other written matter from the company their students work for as classroom materials. Specific needs discovered during the needs assessment phase should also be addressed in a company-specific manner.

EWP is a new and exciting part of the TESOL field. The need for EWP courses grows as companies that hire many non-native speakers of English realize first-hand the shortcomings of federally funded ESL programs that do not allow advanced learning, and that rush students out into the work force to jobs that offer little chance of continued English learning. EWP textbooks can be very useful in workplace courses. What is needed are texts that increase workers flexibility by teaching job search, literacy, and writing skills; texts that promote learner involvement in the workplace by exploring issues that shape their lives, such as unions, rights, discrimination, and intercultural communication; and texts that do not shy away from such topics in an effort to placate company managers. Texts that fail to address these issues perpetuate inequality in our society, mislead students, and render them powerless to transform their lives. 


\section{LIMITATIONS OF THE STUDY}

Several limitations of this study exist. The textbooks evaluated were not actually used by the reviewer--nor were teachers who have used them consulted. Certainly, there is a big leap from theoretical speculation to practical use. Student, teacher, and company responses to the texts would have added greatly to the evaluations made here.

Additionally, several of the texts came with audio and video tapes; other than a short demonstration video tape for English Works, these were not available for review. For some texts, particularly English Works, the video was a crucial component for the text. The audio tapes for Business Venture 1 and Business Objectives included several varieties of English (British, American, Australian). Also, with two exceptions, the reviewer did not have access to teacher-guides. These usually offer more theoretical support, information, and suggestions for classroom procedures.

Finally, no input from publishers about how well these texts sell was included. This information was requested but not received.

\section{IMPLICATIONS AND RECOMMENDATIONS}

There are several implications of this study for the field of EWP. EWP practitioners need to define goals and take stock of what EWP is. Some questions need to be considered such as: Why EWP classes should be developed rather than simply having ESL 
classes at the work site; that is, why design curricula and texts specifically for workplace interaction rather than using non-work-related ESL materials? What is EWP? How is it different from ESP? Also, EWP textbook writers need to find a more humane balance between what management wants and what students need to be flexible, valued, and assertive employees. Most importantly, EWP planners must look at the long-term employment picture not the short-term, thus emphasizing job flexibility and transferable skills.

For EWP practitioners, implications of this study suggest that they need to develop criteria and an evaluation process for text selection. These criteria need to include elements of culture learning, cross-cultural comparison, as well as ways to help learners become active, knowledgeable participants in the work force. Also, the stated goals of the textbook must be weighed in terms of how well they are borne out in the activities and information presented in the lessons.

Implications for the development of EWP materials are that EWP teachers need to develop expertise in creating materials. In company-sponsored and union-sponsored programs teachers need to make lessons specific and authentic for that work site. EWP teachers need to create opportunities and activities for students to talk about their native cultures and make comparisons, express opinions, reflect upon experiences, and plan strategies for action. Additionally, teachers need to be able to supplement texts with pertinent information and learning activities about unions, rights, and intercultural communication. 


\section{REFERENCES}

Auerbach, E. \& Burgess, D. (1985). The hidden curriculum of survival ESL. TESOL Quarterly, 19, (3), 475-493.

Auerbach, E. \& Wallerstein, N. (1987). ESL for action: Problem-posing at work. Reading MA: Addison-Wesley.

Bachman, L.F. (1993). What does language testing have to offer? In, Silberstein, S. (Ed.), State of the art TESOL (pp. 169-202). Alexandria, VA: TESOL.

Barnard, R. \& Cady, J. (1992). Business venture 1. New York: Oxford University Press.

Baskin, M.M. \& Morton, L.W. (1986). Working world: Language and culture of the job market. Orlando, FL: Harcourt Brace \& Co.

Belfoire, M.E. \& Burnaby, B. (1984). Teaching English in the workplace. Ontario: Ontario Institute for Studies in Education Press.

Bell, J. (1984). The Levis Strauss project: Development of a curriculum. TESL Talk, $\underline{13},(4)$ 83-91.

Betten, N. (1976). Polish American steelworkers: Americanization through industry and labor. In, Pozetta, G.E. (Ed.), Americanization, social control, and philanthropy (pp. 1-12). New York: Garland Publishing Inc.

Brems, M. (1991). Working in English: Beginning language skills for the world of work. Illinois: Contemporary Books.

Bruder, M.N. (1978). Evaluation of foreign language textbooks: a simplified procedure. In, Madsen, H.S. \& Bowen, D.J. (Eds.), Adaptation in language teaching (pp. 209-218). Massachusetts: Newbury Publishers.

Byrne, M.B. (1994). Worksills book 1. Englewood Cliffs, New Jersey: Prentice Hall Regents.

Carlson, R.A. (1970). Americanization as an early twentieth century adult education movement. In, Pozetta, G.E. (Ed.), Americanization, social control, and philanthropy (pp. 62-82). New York: Garland Publishing Inc. 
Center For Applied Linguistics. (1983). ESL in the workplace. In, From the classroom to the workplace: Teaching ESL to adults (pp. 77-100). Washington DC: Harcourt Brace Jovonovich, Inc. And the Center For Applied Linguistics.

Damen, L. (1987). Textbook selection and evaluation. In, Culture learning: The fifth dimension in the language classroom (pp. 253-277). Reading MA: AddisonWesley Publishing Co

Deal, T.E. \& Kennedy, P.R. (1982). Corporate cultures: The rites and rituals of corporate life. Reading, MA: Addison-Wesley Publishing Co.

Freire, P. (1970). Pedagogy of the oppressed. New York: Herder and Herder.

Furnborough, P. \& Munns, R. (1984). Communication for training and development. ESP Journal, 3, 97-108.

Giroux, H. (1983). Theory and resistance in education: A pedagogy for the opposition. MA: Bergin and Garvey Publishers, Inc

Goldhaber, S.G. (1986). Organizational communication. Debuque, Iowa: Wm. C. Brown Publishers.

Gowen, S.G. (1992). The politics of workplace literacy: A case study. New York: Teachers College Press.

Gugliemino, L.M. (1991). Adult ESL instruction: A sourcebook. Illinois: Scott, Foresman and Company.

Hammond, M. \& Collins, B. (1991). Self-directed learning: Critical practice. New York: Nichols/GP Publishing.

Hemphill, D., Pfaffenberger, B., \& Hockman, B. (1989). The working culture 1: Cross cultural communication for new Americans. Englewood Cliffs, New Jersey: Prentice Hall Regents.

Hemphill, D., Pfaffenberger, B., \& Hockman, B. (1989). The working culture 2: Career development for new Americans. Englewood Cliffs, New Jersey: Prentice Hall Regents.

Hilles, S. (1991). Adult education. In, M. Celce-Murcia (Ed.), Teaching English as a second or foreign language (pp. 402-416). Massachusetts: Heinle and Heinle Publishers. 
Hofstede, G. (1991). Cultures and organizations: Software of the mind. London: McGraw Hill Book Co.

Hollett, V. (1991). Business objectives. New York: Oxford University Press.

Hutchinson, T. \& Waters, A. (1987). English for specific purposes: A learningcentered approach. Cambridge: Cambridge University Press.

Korman, G. (1965). Americanization at the factory gate. In, Pozetta, G.E. (Ed.), Americanization, social control, and philanthropy (pp. 150-173). New York: Garland Publishing Inc.

Lindeboom, R. (1990). Joblines: ESL reader series. San Francisco, C.A: Pantile Press.

Lopez-Valadez, J Ed (1985). Executive Summary: Immigrant workers in the American workplace: the role of vocational education. ERIC document 260304.

Marsick, V.J. (1988). Learning in the workplace: The case for reflectivity and critical thinking. Adult education quarterly, 38, (4), 187-198.

Marsick, V.J. \& Watkins, K.E. (1993). Paradigms for critically reflective teaching and learning. In, Galbraith, M.W. (Ed.), Facilitating adult learning: A transactional process (). Florida: Kreiger Publishing Co.

McGroarty, M. (1993). Second language learning in the workplace. Annual review of applied linguistics, $13,86-108$.

Mohl, R. \& Betten, N. (1972). Ethnic adjustment in the industrial city: The international institutes of Gary, Indiana 1919-1940. In, Pozetta G.E. (Ed.), Americanization, social control and, philanthropy (pp. 269-285). New York: Garland Publishing Inc.

Molinsky, S.J. \& Bliss, B. (1994). Day by day: English for employment communication. Englewood Cliffs, New Jersey: Prentice Hall Regents.

Moran, R. \& Harris, P.R. (1987). Managing cultural differences. Houston, Texas: Gulf Publishing Co.

Mrowicki, L. (1984). Let's work safely. English skills for safety in the workplace. Illinois: Linmore Publishing, Inc.

Prince, D. (1984). Workplace English: Approach and analysis. ESP Journal, 3 , 109-116. 
Prince, D. \& Gage, J.L. (1986). Your first job: Putting your English to work. Englewood Cliffs: New Jersey.

Quatrini, S.C. (1994). Workskills book 2. Englewood Cliffs, New Jersey: Prentice Hall Regents.

Ramsey, K. \& Robyn, A. (1992). Preparing adult immigrants for work: the educational response in two communities. Rand Note: As 36. R27 N-3586. NCRVE University California, Berkeley.

Robinson, C. \& Rowekamp, J. (1985). Speaking up at work. New York: Oxford University Press.

Robinson, L. (1991). Working in English: A picture-based approach for the world of work. Illinois: Contemporary Books

Rubin, J., McKay, S. \& Mansoor, I. (1995). English Works! Englewood Cliffs, NJ: Addison-Wesley

Sauve, V. (1982). EWP: A study of six projects in Alberta and Ontario. TESL Talk, $13 .(4), 17-23$.

Skierso, A. (1991). Textbook selection and evaluation. In, M. Celce-Murcia (Ed.), Teaching English as a second or foreign language (pp. 432-435). Massachusetts: Heinle and Heinle Publishers.

Shore, I. (1992). Empowering education: Critical teaching for social change. Illinois: University of Chicago Press.

Simon, R.I., Dippo, D., \& Schenke, A. (1991). Learning work: A critical pedagogy of work education. New York: Bergin and Garvey.

Smith, J.H. \& Ringel, H. (1991). The working experience: Book 1. New York: New Readers Press.

Smith, J.H. \& Ringel, H. (1991). The working experience: Book 2. New York: New Readers Press.

Speegle, R. \& Giesecke, W.B. (1983). Business world: A collection of readings on contemporary issues. New York: Oxford University press.

Trebble, M. \& Wallace, D. (1982). English in the union hall. TESL Talk, 13, (4), 101-105. 
West, L.L. (1984). Needs assessment in occupation-specific VESL or how to know what to teach. ESP Journal, 3, 143-152.

Wrigley, H.S. (1987). May I help you? How to interact with the public. Reading, M.A: Addison-Wesley Publishing Co.

U.S. Government Documents. (1987). Workforce 2000: Work and workers for the twenty-first century. Indiana: Hudson Institute. 
APPENDIX A

\section{LIST OF TEXTBOOKS REVIEWED}

1. Let's Work Safely! English Language Skills for Safety in the Workplace by Linda Mrowicki

2. Speaking Up At Work by Catherine Robinson and Jenise Rowekamp

3. ESL For Action: Problem Posing at Work by Elsa Roberts Auerbach and Nina Wallerstein

4. May I Help You? Learning to Interact with the Public by Heide Spruck Wrigley

5. The Working Culture: Book 1 Cross-Cultural Communication for New Americans by David Hemphill, Barbara Pfaffenberger, Barbara Hockman

6. The Working Culture: Book 2 Career Development for New Americans by David Hemphill, Barbara Pfaffenberger, Barbara Hockman

7. Business World: A Collection of Reading on Contemporary Issues by Roger Speegle and William B Giesecke

8. The Working World: Language and Culture of the Job Market by Maria Maniscalaco Baskin, and Lois Wasserman Morton

9. English Works! by Joan Rubin, Sharon McKay, and Inaam Mansoor

10. The Working Experience 1 by Jeanne H Smith, and Harry Ringel

11. The Working Experience 2 by Jeanne H Smith, and Harry Ringel

12. Your First Job: Putting Your English to Work by David W Prince, and Julia Lakey Gage 
13. Business Venture 1 by Roger Barnard, and Jeff Cady

14. Business Objectives by Vicki Hollett

15. Working In English: A Picture-based Approach for the World of Work by Lynne Robinson

16. Working In English: Beginning Language Skills for the World of World by Marianne Brems

17. Day by Day: English for Employment Communication by Steven J Molinsky, and Bill Bliss

18. Workskills Book 1 by Mary Lou Beilfuss Byrne

19. Workskills Book 2 by Susan Quatrini

20. Joblines: ESL Easy Reader Series by Robert Lindeboom 


\section{APPENDIX B}

\section{Checklist for Descriptive Evaluations}

\section{Background Information}

1. Title:

Publisher:

Author:

Price:

Level:

2. Topics covered:

3. Organization:

4. Methodology (if stated)

5. Activities included

6. Additional teaching aides available:

Cultural and Workplace Concerns

Questions seven through thirteen are rated on a scale of 1-5 ( 5 being the highest or most true)

7. Workplace represented as culturally diverse?

8. Intercultural communication addressed?

9. Information about Unions provided?

10. Workplace training addressed?

11. Job advancement and job hunting addressed?

12. Information given about employee rights?

13. Information provided about employee benefits? 


\section{APPENDIX C}

Questions for In-depth Evaluations

1. What cultural items and workplace situations are depicted in the text?

2. What kind of language is represented?

3. How are workplace relationships characterized?

4. How are workplace hierarchies represented?

5. How are unions represented?

6. What cultural attitudes about time are covered? 
7. What topics for conversation are covered?

8. How is intercultural communication facilitated by this text?

9. How does the text encourage the learner to become an active participant in his/her workplace?

10. How does the text address what a worker should do if he/she feels he/she has been a victim of harassment, discrimination, or otherwise treated unfairly? 


\section{APPENDIX D}

\section{PARTIAL LIST OF EWP TEXTBOOK PUBLISHERS}

\section{Publishers}

Oxford University Press

200 Madison Avenue

New York, NY 10016

800-451-7556

Prentice-Hall

200 Old Tappan Road

Old Tappan, NJ 07632

800-947-7700

Contemporary Books

180 Stetson Avenue

Chicago, IL 60601

312-540-4500

Linmore Publishers Inc.

409 South Street

Barrington, IL 60010

Addison-Wesley Publishing Company

South Street

Reading, MA 01876

Center for Applied Linguistics

3520 Prospect Street

Washington, DC 20007
Heinie \& Heinle Publishers Inc. 286 Congress Street

Boston, MA 02210

National Textbook Company

4255 West Touhy Avenue

Lincolnwood, IL 60646

800-323-4900

New Readers Press

PO Box 888

Syracuse, NY 13210

Scott Foresman \& Company

1900 East lake Avenue

Genview, IL 60025

800-732-6657

Harcourt Brace \& Company

6277 Sea Harbor Drive

Orlando, FL 32887

800-742-5375

Heinle \& Heinle Publishers

20 Park Plaza

Boston, MA 02116

800-278-2574 


\section{ARE}

COVERED

WORKERS'

RIGHTS

IS INTER

CULTURAL

COMMUNICA-

ARE JOB

ADVANCE-

a,c.j,k, , l,n

opical, competency- 1,3

based

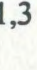

centered

$-\checkmark$

ADDRESSED?

HUNTING

ADDRESSED?

Linmore Publishers

$\$ 8.25$

Speaking Up At

Work

(not stated)

low-intermediate

listening/speaking, topical,

both work- and

$1,2,3,4,5,7,8$

a,b,c, d,i.j,k,l,n

- $\checkmark$

$--\checkmark$

ARE UNIONS

ADDRESSED?

ADDITIONAL

TEACHING

AIDS

AVAILABLE

Teacher's

Manual

Teacher's Manual

Oxford Univ. Press

Jenise Rowekam

Jenise Rowekamp

ESL For Action

Addison-Wesley

Elsa Auerbach \&

May I Help You?

Addison-Wesley

Heide Spruck

Wrigley

$\$ 11.95$

The Working

Culture Book One

Prentice Hall

David Hemphill,

Barbara

Pfaffenberger, \&

Barbara Hockman

unctional

$\cdots$

intermediate to

lives of workers.

problem-posing,

idvand

worker-centered

competency- based

intermediate

listening/speaking topical

eservice industries, function

low-intermediate

cross-cultural

communication

theme-based,

problem-posing

competency-based
$3,6,8$ eang and

Teacher's Manual, cassette tape

Teacher's Guide

KEY TOPICS:

TOPICS:

2. non-verbal communicatio

3. communication at work

4. social relations at work

5. telephoning

6. employee performance reviews

7. pay

8. culture

ACTIVITIES:
a. dialogues
b. discussion
c. role-plays
d. outside of classroom activities
e. peer evaluations
f. case studies
g. numbers and cal culations
h. information gap activities

i. listening
j. writing
k. readings
1. reading graphs ind charts
m. vocabulary
n. structure
o. cross-cultural o mparison
p. debates

RATING SYSTEM:

$++\quad$ very well covered

$\checkmark+$ well covered

$\checkmark \quad$ adequately covered

- poorly covered

-. very poorly covered, or

h. information gap activities 


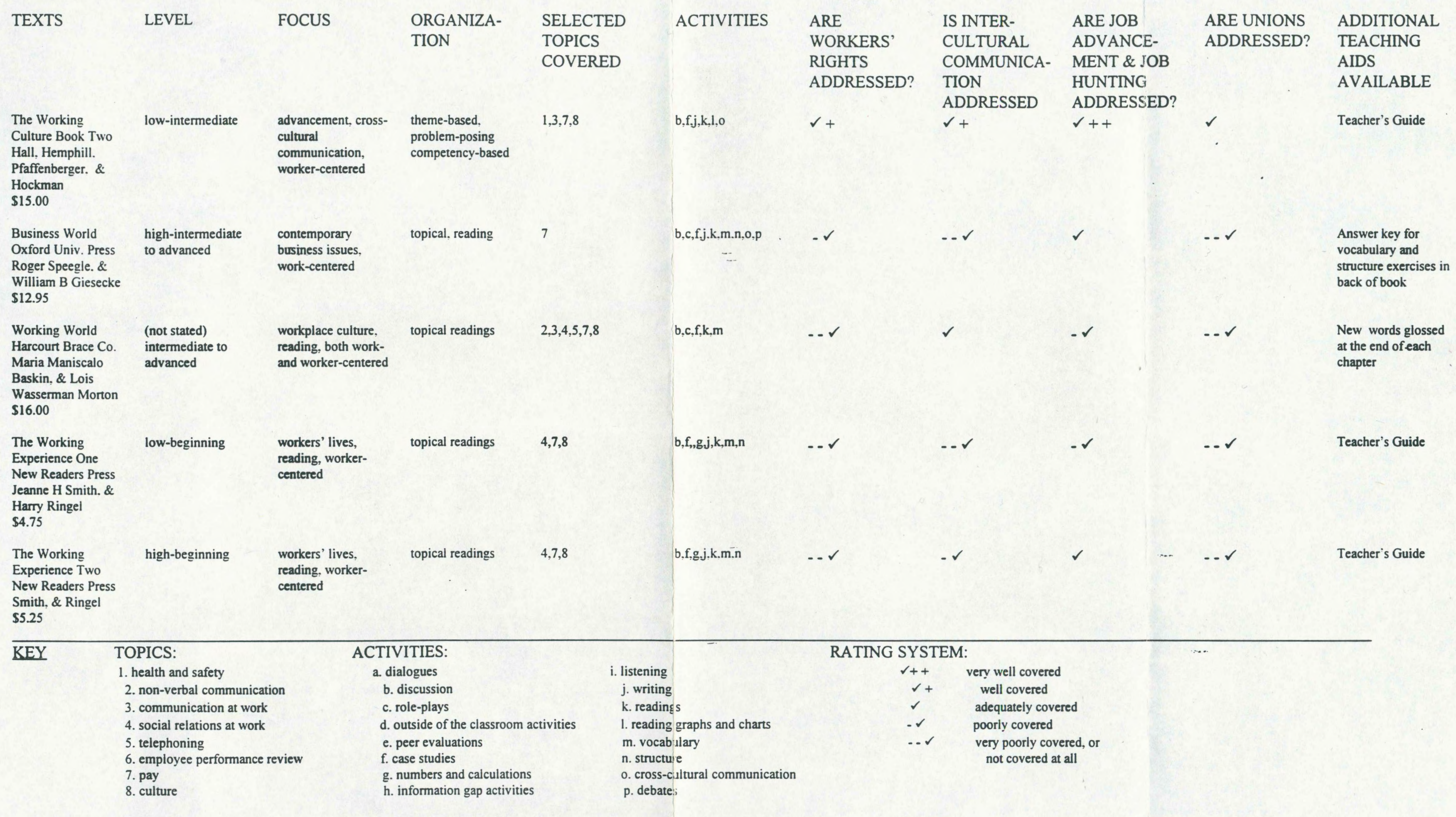




\begin{tabular}{|c|c|c|c|c|c|c|c|c|c|c|}
\hline TEXTS & LEVEL & FOCUS & $\begin{array}{l}\text { ORGANIZA- } \\
\text { TION }\end{array}$ & $\begin{array}{l}\text { SELECTED } \\
\text { TOPICS } \\
\text { COVERED }\end{array}$ & ACTIVITIES & $\begin{array}{l}\text { ARE } \\
\text { WORKERS' } \\
\text { RIGHTS } \\
\text { ADDRESSED? }\end{array}$ & $\begin{array}{l}\text { IS INTER- } \\
\text { CULTURAL } \\
\text { COMMUNICA- } \\
\text { TION } \\
\text { ADDRESSED? }\end{array}$ & $\begin{array}{l}\text { ARE JOB } \\
\text { ADVANCE- } \\
\text { MENT \& JOB } \\
\text { HUNTING } \\
\text { ADDRESSED? }\end{array}$ & $\begin{array}{l}\text { ARE UNIONS } \\
\text { ADDRESSED? }\end{array}$ & $\begin{array}{l}\text { ADDITIONAL } \\
\text { TEACHING } \\
\text { AIDS } \\
\text { AVAILABLE }\end{array}$ \\
\hline $\begin{array}{l}\text { English Works! } \\
\text { Addison-Wesiey } \\
\text { Joan Rubin. Sharon } \\
\text { McKay, \& Inaam } \\
\text { Mansoor } \\
\text { \$9.00 }\end{array}$ & high-beginning & listening/speaking, & topical, functional, & $1,2,3,4,8$ & $a, b, z, d, f, i$ & $\ldots r$ & $\checkmark$ & $\checkmark$ & $\ldots r$ & Video tape \\
\hline $\begin{array}{l}\text { Your First Job } \\
\text { Prentice Hall } \\
\text { David W Prince. \& } \\
\text { Julia Lakey Gage }\end{array}$ & $\begin{array}{l}\text { (not stated) } \\
\text { beginning to } \\
\text { high beginning }\end{array}$ & $\begin{array}{l}\text { manufacturing jobs. } \\
\text { work-centered }\end{array}$ & topical, functional & $1.3,4,6,7$ & a.b.i & $-r$ & $\ldots r$ & $-r$ & $\ldots r$ & Teacher's Manual \\
\hline $\begin{array}{l}\text { Business Venture } 1 \\
\text { Oxford Univ. Press } \\
\text { Roger Barmard, \& } \\
\text { Jeff Cady } \\
\text { \$12.95 }\end{array}$ & $\begin{array}{l}\text { high-beginning to } \\
\text { intermediate }\end{array}$ & $\begin{array}{l}\text { business, both work- } \\
\text { and worker-centered }\end{array}$ & topical, functional & $3,4,5,8$ & $a, b, c, g, h, i, j, l$ & $\ldots r$ & $\checkmark+$ & $\checkmark$ & $\ldots r$ & $\begin{array}{l}\text { Cassette tape, } \\
\text { transcript. answer } \\
\text { key }\end{array}$ \\
\hline $\begin{array}{l}\text { Business Objectives } \\
\text { Oxford Univ. Press } \\
\text { Vicki Hollett } \\
\text { \$12.95 }\end{array}$ & low-intermediate & $\begin{array}{l}\text { business, work- } \\
\text { centered }\end{array}$ & topical, functional & $3,4,5$ & $\mathrm{~b}, \mathrm{c}, \mathrm{h}, \mathrm{i}, \mathrm{j}, \mathrm{l}, \mathrm{l,n}, \mathbf{p}$ & $\ldots r$ & $-\checkmark$ & $--r$ & $--r$ & $\begin{array}{l}\text { Cassette tape, } \\
\text { transcript, answer } \\
\text { key, teacher's } \\
\text { manual, glossary of } \\
\text { business terms, } \\
\text { grammatical } \\
\text { summary }\end{array}$ \\
\hline $\begin{array}{l}\text { Working In English } \\
\text { Book One } \\
\text { Contemporary } \\
\text { Books } \\
\text { Lynne Robinson } \\
\text { \$7.95 }\end{array}$ & beginning & listening/speaking, & competency-based & $3,6,7$ & b.h.n & $\ldots r$ & $-r$ & $\checkmark+$ & $\ldots r$ & Teacher's Guide \\
\hline KEY & $\begin{array}{l}\text { TOPICS: } \\
\text { 1. health and safety } \\
\text { 2. non-verbal communicatio } \\
\text { 3. communication at work } \\
\text { 4. social relations at work } \\
\text { 5. telephoning } \\
\text { 6. employee performance re } \\
\text { 7. pay } \\
\text { 8. culture }\end{array}$ & $\begin{array}{l}\text { ACTIV } \\
\text { a. dia } \\
\text { b. } \\
\text { c. r } \\
\text { d. } \\
\text { e. } \\
\text { f. c } \\
\text { g. } \\
\text { h. }\end{array}$ & $\begin{array}{l}\text { ITIES: } \\
\text { logues } \\
\text { discussion } \\
\text { ole-plays } \\
\text { utside of the ciassroo } \\
\text { peer evaluations } \\
\text { ase studies } \\
\text { umbers and calculati } \\
\text { information gap activi }\end{array}$ & activities & $\begin{array}{l}\text { ing } \\
\text { iting } \\
\text { adings } \\
\text { ding graphs and charts } \\
\text { ocabulary } \\
\text { ucture } \\
\text { ss-cultiral comparison } \\
\text { bates }\end{array}$ & 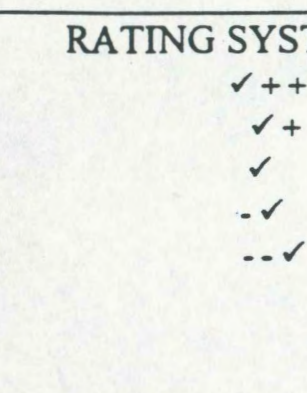 & $\begin{array}{l}\text { EM: } \\
\text { very well covered } \\
\text { well covered } \\
\text { adequately covere } \\
\text { poorly covered } \\
\text { very poorly cover } \\
\text { not covered at a }\end{array}$ & ed & & \\
\hline
\end{tabular}




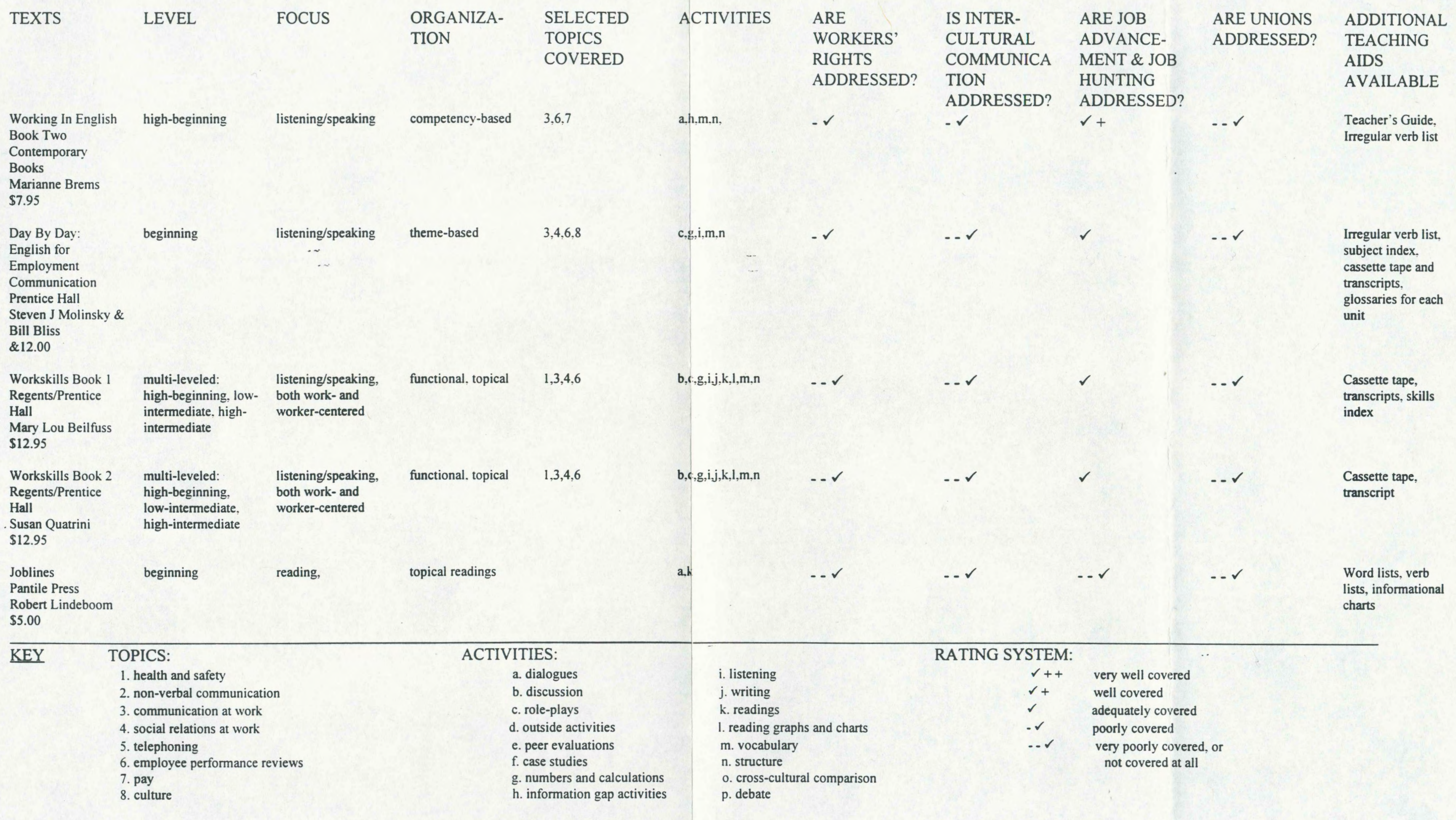

